$$
\begin{gathered}
\text { UNIVERSIDADE DE SÃO PAULO } \\
\text { FACULDADE DE CIÊNCIAS FARMACÊUTICAS } \\
\text { Programa de Pós-Graduação em Fármaco e Medicamentos } \\
\text { Área de Produção e Controle Farmacêuticos }
\end{gathered}
$$

\title{
Desenvolvimento e otimização de sistemas conservantes empregando os conceitos de Qualidade por Design (QbD) e Tecnologia Analítica de Processos (PAT)
}

Camila Francini Fidelis Pinto

MESTRADO

Orientador: Prof. Felipe Rebello Lourenço

São Paulo - 2019 



\author{
UNIVERSIDADE DE SÃO PAULO \\ FACULDADE DE CIÊNCIAS FARMACÊUTICAS \\ Programa de Pós-Graduação em Fármaco e Medicamentos \\ Área de Produção e Controle Farmacêuticos
}

\title{
Desenvolvimento e otimização de sistemas conservantes empregando os conceitos de Qualidade por Design (QbD) e Tecnologia Analítica de Processos (PAT)
}

Camila Francini Fidelis Pinto

\author{
Versão Corrigida \\ Dissertação para obtenção do Título de Mestre \\ Orientador: Prof. Dr. Felipe Rebello Lourenço
}

São Paulo - 2019 
Ficha Catalográfica elaborada eletronicamente pelo autor, utilizando o programa desenvolvido pela Seção Técnica de Informática do ICMC/USP e adaptado para a Divisão de Biblioteca e Documentação do Conjunto das Quimicas da USP

Bibliotecária responsável pela orientação de catalogação da publicação: Marlene Aparecida Vieira - CRB - 8/5562

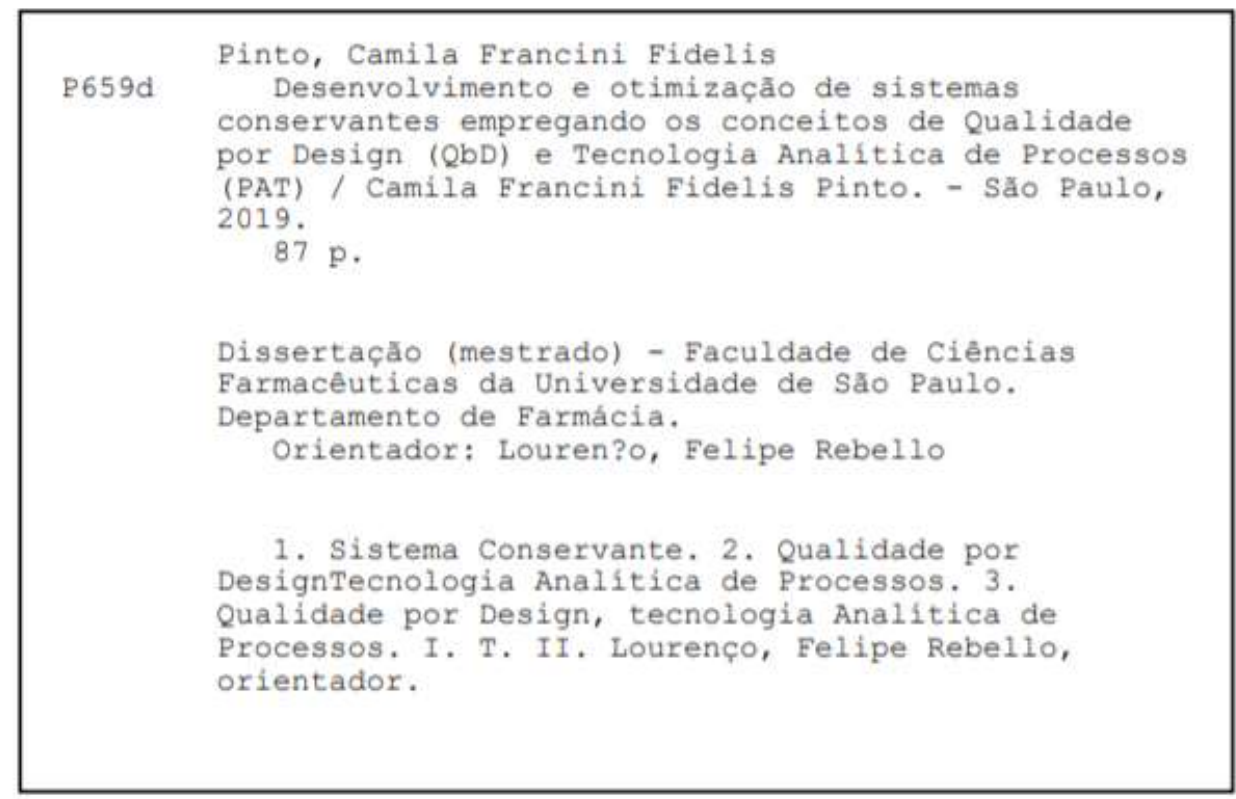


Camila Francini Fidelis Pinto

\title{
Desenvolvimento e otimização de sistemas conservantes empregando os conceitos de Qualidade por Design (QbD) e Tecnologia Analítica de Processos (PAT)
}

\author{
Comissão Julgadorada
}

Dissertação para obtenção do Título de Mestre

Prof. Dr. Felipe Rebello Lourenço orientador/presidente

10. examinador

$2^{\circ}$. Examinador

$3^{\circ}$. Examinador

São Paulo, de de 

Não sei... se a vida é curta

Ou longa demais pra nós,

Mas sei que nada do que vivemos

Tem sentido, se não tocamos o coração das pessoas..."

\section{Cora Coralina}



À Deus, por sempre me guiar, iluminar e proteger a minha vida. Aos meus pais, Perpétua e Fernando, por todo amor, dedicação, formação e orientação, por acreditarem em mim e me apoiarem em todos os momentos.

À minha irmã Juliana, parte fundamental para a realização deste projeto, por todo seu empenho e dedicação.

Ao meu marido e companheiro de todas as horas, Rafael, por todo seu amor, respeito e cumplicidade. 

A todos os meus familiares, não citarei nomes, para não me esquecer de ninguém. Mas há aquelas pessoas especiais que diretamente me incentivaram. Aos modelos em que procuro me espelhar sempre: aos meus queridos avôs maternos, Vicentina e Francisco, amor incondicional eterno, e por me terem ensinado a ser nobre, na essência da palavra. Aos avós paternos, Maria Aparecida pela garra e perseverança, e Luiz (in memoriam) que mesmo não o conhecendo sei que está olhando por mim.

Ao meu orientador Prof ${ }^{o}$ Felipe Rebello Lourenço, pelo incentivo, orientação, confiança e amizade dispensados na realização deste trabalho.

À aluna de iniciação científica e também minha irmã, Juliana, que muito contribuiu para realização deste trabalho.

À professora Terezinha de Jesus Andreoli, pelo empenho e determinação em propiciar disponibilidade no suporte técnico e material.

Ao CONFAR - Laboratório de Controle de Medicamentos, Cosméticos, Domissanitários e Produtos Afins, por disponibilidade em suporte técnico e material.

À professora Marina Ishii e ao professor Luiz Carlos Martins das Neves, por me introduzirem na área acadêmica.

Ao Edgar Muniz Machado Junior, pelo apoio na parte técnica e por atender minhas solicitações.

Ao Departamento de Farmácia da Faculdade de Ciências Farmacêuticas da USP, pela oportunidade do desenvolvimento desta pesquisa.

A todos que colaboraram na execução deste trabalho. 



\section{RESUMO}

PINTO, C.F.F. Desenvolvimento e otimização de sistemas conservantes empregando os conceitos de Qualidade por Design (QbD) e Tecnologia Analítica de Processos (PAT). 2019. 87p. Dissertação para obtenção do Título de Mestre - Departamento de Farmácia, Faculdade de Ciências Farmacêuticas, Universidade de São Paulo, São Paulo, 2019.

Recentemente, produtos farmacêuticos e cosméticos com concentrações mínimas de parabenos e outros conservantes ganharam e apelo comercial e de segurança, devido à controvérsia sobre a segurança dos conservantes. No entanto, o uso de conservantes é essencial para garantir a conservação microbiana de produtos cosméticos e farmacêuticos durante o seu uso. Neste trabalho, desenvolveu-se um método quimiométrico de espectroscopia no infravermelho com Fourier transform near-infrared (FTIR) para prever a eficácia de sistemas conservantes em produtos farmacêuticos e cosméticos tópicos usando os conceitos de Quality by design (QbD) e Process Analytical Technology (PAT). A abordagem de QbD foi usada para determinar a eficácia antimicrobiana frente aos microrganismos: Candida albicans (ATCC 10231), Escherichia coli (ATCC 8739) e Staphylococcus aureus (ATCC 6538), em funções das concentrações de parabenos, e determinar a região de Design Space, empregando o delineamento de compóstio central (CCD) Todas as 15 formulações preparadas foram analisadas utilizando um espectrofotômetro (FTIR) equipado com aparato de Attenuated Total Reflectance (ATR). Os modelos de regressão por Partial Least Squares (PLS) para predição dos "slopes" das curvas de morte microbiana em função dos espectros ATR/FTIR foram bem ajustados, com $\mathrm{R}^{2}$ e $\mathrm{R}^{2}$-predição de 0,9937 e $0,8921,0,9947$ e 0,8783 , e 0,9957 e 0,9222 para Candida albicans (ATCC 10231), Escherichia coli (ATCC 8739) e Staphylococcus aureus (ATCC 6538), respectivamente. O método FTIR proposto aplicado em uma abordagem de PAT foi capaz de prever a eficácia do sistema conservante em tempo reduzido. Este método de predição de silício permitirá um controle lote-a-lote da eficácia do sistema conservante de produtos farmacêuticos e cosméticos.

Palavras-chaves: Sistema Conservante, Qualidade por Design, tecnologia Analítica de Processos 



\begin{abstract}
PINTO, C.F.F. Development and optimization of preservative systems using Quality by Design (QbD) and Process Analytical Technology (PAT) concepts. 2019. 87p. Dissertation for Master degree - Department of Pharmacy, School of Pharmaceutical Sciences, University of São Paulo, São Paulo, 2019.

Recently, pharmaceuticals and cosmetics with minimal concentrations of parabens and other preservatives have gained and commercial and safety appeal due to controversy over the safety of preservatives. However, the use of preservatives is essential to ensure the microbial conservation of cosmetic and pharmaceutical products during use. In this work, a chemometric method of infrared spectroscopy with Fourier transform (FTIR) was developed to predict the effectiveness of preservative systems in pharmaceutical products and topical cosmetics using the concepts of Quality by design (QbD) and Process Analytical Technology (PAT). The QbD approach was used to determine antimicrobial efficacy against candida albicans (ATCC 10231), Escherichia coli (ATCC 8739) and Staphylococcus aureus (ATCC) microorganisms 6538), in functions of paraben concentrations, and determine the Design Space region, employing the design of central composite (CCD). All 15 prepared formulations were analyzed using a spectrophotometer (FTIR) equipped with Attenuated Total Reflectance (ATR). The Partial Least Squares (PLS) regression models for the prediction of the slopes of microbial death curves as a function of ATR /FTIR spectra were well adjusted, with $\mathrm{R}^{2}$ and $\mathrm{R}^{2}$-prediction 0.9937 and 0.8921, 0.9947 and 0.8783, and 0.9957 and 0.9222 for Candida albicans (ATCC 10231), Escherichia coli (ATCC 8739) and Staphylococcus aureus (ATCC 6538)respectively. The proposed FTIR method applied in a PAT approach was able to predict the effectiveness of the preservative system in reduced time. This method in silico prediction will allow a batch-to-lot control of the effectiveness of the preservative system of pharmaceuticals and cosmetics.
\end{abstract}

Keywords: Preservative system, Quality by Design, Process Analytical Technology 



\section{SUMÁRIO}

1. INTRODUÇÃ

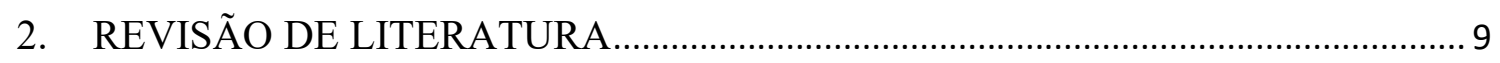

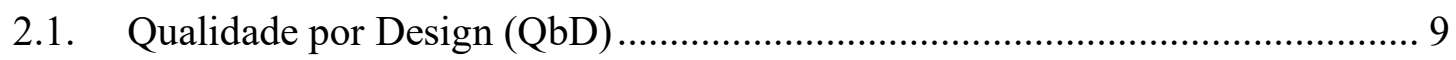

2.1.1. Quality Target Product Profile (QTPP) ............................................ 14

2.1.2. Atributo Críticos de Qualidade (Critical Quality Atributes - CQAs), Parâmetros Críticos de Processo (Critical Process Parameters - CPPs), Atributos Críticos de Materiais (Critical Material Atributes - CMAs) .............. 15

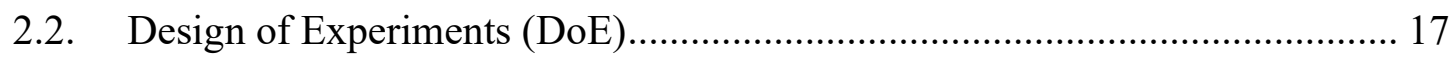

2.2.1. Delineamento de Compósito Central - CCD .................................. 19

2.3. Process Analytical Technology (PAT) ..................................................... 20

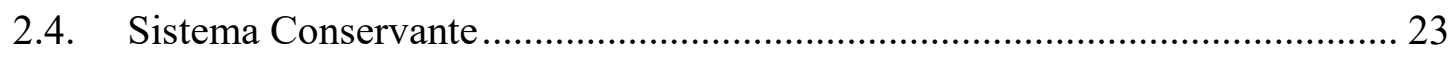

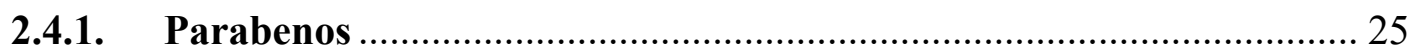

2.5. Teste de Eficácia de Conservantes................................................................ 30

2.5.1. Técnica do Número de Mais Provável ................................................. 31

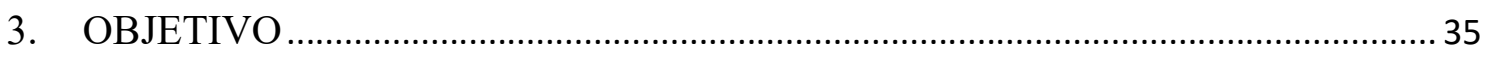

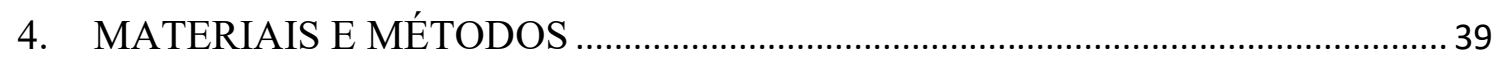

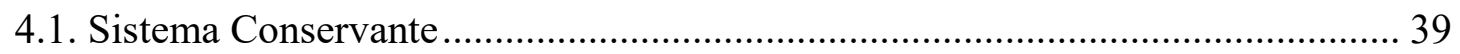

4.2.1. Obtenção e padronização de suspensão microbiana .................................... 39

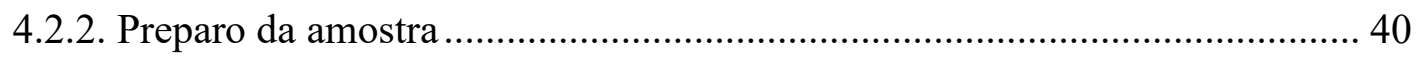


4.2.3. Avaliação da eficácia dos conservantes através de microdiluição em caldo 40

4.2.4. Avaliação da atividade inibitória dos agentes neutralizantes. 42

4.3. Otimização da avaliação da eficácia de conservantes empregando QbD 42

4.4. Desenvolvimento de método espectrométrico empregando PAT. 44

5. RESULTADOS E DISCUSSÃO 49

6. CONCLUSÕES . 81

7. REFERÊNCIAS. .85 


\section{LISTA DE FIGURAS}

Figura 1. Ilustração da aplicação de Qualidade por Design (QbD) no desenvolvimento de produto e processo.

Figura 2. Exemplificação gráfica de pontos Fatoriais, Axiais e Centrais. 19

Figura 3. Estrutura química dos parabenos comumente utilizados como conservantes em formulações farmacêuticas e cosméticas..

Figura 4. Esquema de distribuição das diluições $\left(10^{-2}\right.$ a $\left.10^{-6}\right)$ para as alíquotas testadas imediatamente após a incubação inicial (T0), e após 1h (T1), 2hs (T2), 4hs (T3), 24hs (T4), 48 hs (T5) e 72 horas (T6) após as formulações terem sido inoculadas com Candida albicans (ATCC 10232), Escherichia coli (ATCC 8739), e Staphylococcus aureus (ATCC 6538).

Figura 5. Gráficos de redução da carga microbiana ao longo do tempo para Candida albicans nas formulações de F1 a F8.

Figura 6. Gráficos de redução da carga microbiana ao longo do tempo para Escherichia coli nas formulações de F1 a F8

Figura 7. Gráficos de redução da carga microbiana ao longo do tempo para Staphylococcus aureus nas formulações de F1 a F8.

Figura 8. Gráficos 3D dos "slopes" para Candida albicans (Y1) em função das concentrações de metilparabeno (X1), propilparabeno (X2) e isobutilparabeno (X3). Valores fixados em X $1=0,025 \%, \mathrm{X} 2=0,025 \%$ e X3 $=0,025 \%$

Figura 9. Gráficos 3D dos "slopes" para Escherichia coli (Y2) em função das concentrações de metilparabeno (X1), propilparabeno (X2) e isobutilparabeno (X3). Valores fixados em X1 $=0,025 \%, \mathrm{X} 2=0,025 \%$ e X3 $=0,025 \%$ 
Figura 10. Gráficos 3D dos "slopes" para Staphylococcus aureus (Y3) em função das concentrações de metilparabeno (X1), propilparabeno (X2) e isobutilparabeno (X3). Valores fixados em X1 $=0,025 \%, \mathrm{X} 2=0,025 \%$ e X3 $=0,025 \%$.

Figura 11. Gráficos 3D do tempo necessário para redução de 3 ciclos log para Candida albicans (Y1) em função das concentrações de metilparabeno (X1), propilparabeno (X2) e isobutilparabeno (X3). Valores fixados em X1 $=0,025 \%, \mathrm{X} 2=0,025 \%$ e X3 = $0,025 \%$

Figura 12. Gráficos 3D do tempo necessário para redução de 3 ciclos log para Escherichia coli (Y2) em função das concentrações de metilparabeno (X1), propilparabeno (X2) e isobutilparabeno (X3). Valores fixados em X1 $=0,025 \%, \mathrm{X} 2=0,025 \%$ e X3 $=$ $0,025 \%$

Figura 13. Gráficos 3D do tempo necessário para redução de 3 ciclos log para Staphylococcus aureus (Y3) em função das concentrações de metilparabeno (X1), propilparabeno (X2) e isobutilparabeno (X3). Valores fixados em X1 $=0,025 \%, \mathrm{X} 2$ $=0,025 \%$ e X3 $=0,025 \%$.

Figura 14. Gráficos de Pareto e de Efeitos Principais do tempo necessário para redução de 3 ciclos $\log$ para Candida albicans (Y1), Escherichia coli (Y2) e Staphylococcus aureus (Y3) em função das concentrações de metilparabeno (X1), propilparabeno (X2) e isobutilparabeno (X3). Valores fixados em X1 $=0,025 \%, \mathrm{X} 2=0,025 \%$ e X3 $=0,025 \%$

Figura 15. Gráficos de contorno sobrepostos do tempo necessário para redução de 3 ciclos log para Candida albicans (Y1), Escherichia coli (Y2) e Staphylococcus aureus (Y3) em função das concentrações de metilparabeno (X1), propilparabeno (X2) e isobutilparabeno (X3)

Figura 16. Espectros de FTIR de formulações (F1 a F15) na região de 800 a $2600 \mathrm{~cm}^{-1}$ utilizados para construir o modelo de regressão PLS para prever os "slopes" das curvas de morte microbiana de Candida albicans (Y1), Escherichia coli (Y2), e Staphylococcus aureus (Y3) 
Figura 17. Gráficos de resposta (capacidade de predição) para o ajuste do modelo $(\bullet)$, validação interna - cruzada $(\bullet)$, e validação externa ( ) para a predição dos "slopes" para Candida albicans a partir dos espectros de IR......................................

Figura 18. Gráficos de resposta (capacidade de predição) para o ajuste do modelo $(\bullet)$, validação interna - cruzada $(\bullet)$, e validação externa ( $)$ para a predição dos "slopes" para Escherichia coli a partir dos espectros de IR

Figura 19. Gráficos de resposta (capacidade de predição) para o ajuste do modelo $(\bullet)$, validação interna - cruzada $(\bullet)$, e validação externa ( ) para a predição dos "slopes" para Staphylococcus aureus a partir dos espectros de IR 



\section{LISTA DE TABELAS}

Tabela 1. Resumo das características dos delineamentos de triagem e otimização, considerando o número de experimentos necessários, o número de níveis de fatores de entrada e os números de fatores a serem estudados.

Tabela 2. Propriedades físico-química dos parabenos comumente utilizados como conservantes em formulações farmacêuticas e cosméticas

Tabela 3. Concentração de uso dos parabenos comumente utilizados como conservantes em formulações farmacêuticas e cosméticas.

Tabela 4. Concentração de conservantes empregados no preparo das formulações, de acordo com o planejamento de experimentos adotado

Tabela 5. Controle positivo para inativação do sistema conservante.

Tabela 6. Recuperação microbiana frente a inativação do sistema conservante

Tabela 7. Resultados dos "slopes" obtidos a partir das curvas de morte microbiana de Candida albicans (Y1), Escherichia coli (Y2) e Staphylococcus aureus (Y3), em função das concentrações de metilparabeno (X1), propilparabeno (X2) e isobutilparabeno $(\mathrm{X} 3)$..

Tabela 8. Resultados de ANOVA para os "slopes" obtidos a partir das curvas de morte microbiana de Candida albicans (Y1), Escherichia coli (Y2) e Staphylococcus aureus (Y3), em função das concentrações de metilparabeno (X1), propilparabeno (X2) e isobutilparabeno (X3). 
Tabela 9. Equações de regressão e coeficientes de determinação das velocidades de morte das formulações contendo diferentes concentrações de metilparabeno, propilparabeno e isobutilparabeno.

Tabela 10. Resultados do tempo necessário para redução de 3 ciclos log para Candida albicans (Y1), Escherichia coli (Y2 e Staphylococcus aureus (Y3), em função das concentrações de metilparabeno (X1), propilparabeno (X2) e isobutilparabeno (X3)

Tabela 11. Resultados de ANOVA para o tempo necessário para redução de 3 ciclos log para Candida albicans (Y1), Escherichia coli (Y2) e Staphylococcus aureus (Y3), em função das concentrações de metilparabeno (X1), propilparabeno (X2) e isobutilparabeno (X3).

Tabela 12. Equações de regressão e coeficientes de determinação das velocidades de morte das formulações contendo diferentes concentrações de metilparabeno (X1), propilparabeno (X2) e isobutilparabeno (X3).

Tabela 13. Teste de eficácia de conservantes segundo as farmacopeias americana e brasileira para a formulação otimizada contendo metilparabeno $(\mathrm{X} 1=0,025 \%)$, propilparabeno $(\mathrm{X} 2=0,025 \%)$ e isobutilparabeno $(X 3=0,025 \%)$.

Tabela 14. Resumo dos resultados da análise de regressão por mínimos quadrados parciais (PLS) para a predição das velocidades de morte de cada microrganismo 


\section{LISTA DE SIGLAS E ABREVEATURAS}

\begin{tabular}{|c|c|}
\hline ANOVA & Análise de Variância \\
\hline ANVISA & Agência Nacional de Vigilância Sanitária \\
\hline ATCC & American Type Culture Collection \\
\hline ATR & Attenuated Total Reflectance \\
\hline $\mathrm{BPF}$ & Boas Práticas de Fabricação \\
\hline $\mathrm{CCC}$ & Compósito Central Circunscrito \\
\hline $\mathrm{CCD}$ & Central Composite Design \\
\hline CCI & Compósito Central Inscrito \\
\hline $\mathrm{CCF}$ & Compósito Central Faceado \\
\hline $\mathrm{CCS}$ & Compósito Central Scalado \\
\hline CMAs & Critical Material Atributes \\
\hline CPPs & Critical Process Parameters \\
\hline CQAs & Critical Quality Atributes \\
\hline DNA & Deoxyribonucleic acid \\
\hline DoE & Design of Experiments \\
\hline FDA & Food and Drug Administration \\
\hline FT-NIR & Fourier transform near-infrared \\
\hline $\mathrm{F} 1$ & Formulação 1 \\
\hline $\mathrm{F} 2$ & Formulação 2 \\
\hline F3 & Formulação 3 \\
\hline F4 & Formulação 4 \\
\hline F5 & Formulação 5 \\
\hline
\end{tabular}




\begin{tabular}{|c|c|}
\hline F6 & Formulação 6 \\
\hline F7 & Formulação 7 \\
\hline F8 & Formulação 8 \\
\hline QbD & Quality by design \\
\hline QbT & Quality by testing \\
\hline GMP & Good Manufacturing Practice \\
\hline $\mathrm{gL}$ & Graus de liberdade \\
\hline $\mathrm{ICH}$ & International Council for Harmonisation \\
\hline IV & Infravermelho \\
\hline NMP & Número de Mais Provável \\
\hline OMS & Organização Mundial da Saúde \\
\hline PAT & Process Analytical Technology \\
\hline PCA & Resolução da Diretoria Colegiada \\
\hline PLS & Partial Least Squares \\
\hline PREESS & Predicted Residual Error Sum of Squares \\
\hline QTPP & Quality Target Product Profile \\
\hline $\mathrm{RDC}$ & \\
\hline RNA & Ribonucleic acid \\
\hline RSM & Response Surface Methodology \\
\hline $\mathrm{R} 2$ & Coeficiente de determinação \\
\hline R2adj & Coeficiente de determinação ajustado \\
\hline R2pred & Coeficiente de determinação predito \\
\hline SQ & Soma dos Quadrados \\
\hline $\mathrm{UV} / \mathrm{Vis}$ & Espectroscopia no ultravioleta visível \\
\hline
\end{tabular}


Candida albicans

$\mathrm{Y} 2$

Escherichia coli

Y3 Staphylococcus aureus

X1 Metilparabeno

X2 Propilparabeno

X3 Isobutilparabeno

xxvii 

INTRODUÇÃO 



\section{INTRODUÇÃO}

A indústria farmacêutica utiliza um conjunto de normas que ajuda a manter um Sistema de Garantia da Qualidade que cumpra com as exigências regulamentares visando à obtenção de um produto dentro do trinômio qualidade, eficácia e segurança (BRASIL, 2010).

Entende-se como qualidade todas as características de um produto que lhe confere a capacidade de satisfazer as necessidades sejam explicitas ou implícitas (ASSOCIAÇÃO BRASILEIRA DE NORMAS TÉCNICAS, 2008). O termo "boa qualidade" tem como objetivo principal expressar a excelência de um produto que cumpre às especificações quantitativas e qualitativas determinadas pelos órgãos reguladores (SIMÕES, 2008).

As Boas Práticas de Fabricação são elaboradas pelas agências regulatórias, sendo que no Brasil, a Agência de Vigilância Sanitária (ANVISA) tem por objetivo assegurar que os produtos são produzidos e controlados, com padrões de qualidade apropriados para o uso pretendido e requerido pelo registro. Com isso, o seu cumprimento diminuirá os riscos ligados a produção farmacêutica, dos quais muitas vezes não podem ser detectados através de ensaios realizados em produto acabado ou não são perceptíveis por seus consumidores. As Boas Práticas de Fabricação tem por objetivo assegurar que a indústria execute suas ações em conformidade com as expectativas dos órgãos reguladores, garantindo assim, o controle total da qualidade de produtos, sejam eles farmacêuticos, correlatos ou cosméticos, de modo a projetar (design), produzir, manter e assegurar as características especificadas do produto durante a sua distribuição e comercialização (PINTO, KANEKO, \& PINTO, 2015). 
Para se ter um consenso quanto às especificações técnicas e as Boas Práticas de Fabricação, e assim conduzir a qualidade do produto, normas compendiais, como por exemplo a Brasileira são, em grande parte, harmonizadas, fazendo assim com que ocorra a simplificação de programas de integração (PORTARIA n ${ }^{0}$ 782/2008). Entre as normas aceitas internacionalmente podemos citar as Boas Práticas de Fabricação (BPF), publicadas pela Organização Mundial de Saúde (OMS) e as Good Manufacturing Practices (GMP), publicada pela Food and Drug Administration (FDA), agência reguladora de medicamentos e alimentos dos Estados Unidos (OMS 2003, FDA 2019).

A Conferência Internacional de Harmonzação (ICH - International Conference on Harmonization) teve início em 1996, com o intuito de tornar o desenvolvimento de um produto farmacêutico, bem como os processos de registro, mais eficientes e com melhor custo-benefício. A ICH, juntamente com os Estados Unidos, Europa e Japão discutiram e preparam 3 diretrizes: ICH Q8, ICH Q9, e ICH Q10. Tais diretrizes tem como objetivo unificar procedimentos quanto ao desenvolvimento farmacêutico, gestão de risco para a qualidade e sistema da qualidade farmacêutico (ICH Q8, 2009; ICH Q9, 2005; ICH Q10, 2008).

As diretrizes ajudam minimizar os riscos derivados de mudanças durante todo o processo incluindo as etapas de desenvolvimento, fazendo assim a integração no Sistema de Gestão da Qualidade, com foco na melhoria contínua durante todo o ciclo de vida do produto, através de ações como avaliação, controle, comunicação e revisão do risco (ICH Q8, 2009; ICH Q9, 2005; ICH Q10, 2008).

No Brasil, o conceito de sistema de gestão da qualidade durante toda a etapa de desenvolvimento teve início através da agência Nacional de Vigilância Sanitária (ANVISA), após a vigência da Resolução RDC n 60 de 10 de outubro de 2014, que 
dispõem aos fabricantes de medicamentos os requisitos para a implementação de conceitos como gerenciamento de risco e monitoramento periódico de desempenho do produto durante todo seu ciclo de vida útil. Já na indústria cosmética há uma busca pela qualidade, garantindo assim a produção de cosméticos seguros, eficazes e benéficos, de modo que a qualidade do produto seja contemplada ao longo de toda a cadeia produtiva através de ensaios do controle qualidade que garantam a satisfação do consumidor ao adquirir os produtos da área da beleza (PINTO, ALPIOVEZZA, RIGHETTI, 2012).

A Food and Drug Administration (FDA) tem incentivado o emprego de ferramentas inovadoras baseadas na construção da qualidade ao longo do desenvolvimento e otimização de produtos, denominada qualidade por Design (Quality by Design - QbD). Desde a introdução dos conceitos de QbD, tem sido aceito que a qualidade dos produtos farmacêuticos e cosméticos devem ser projetados e construídos durante o processo de fabricação. De acordo com Yuran (Yu ET AL., 2014) grande parte dos problemas de qualidade estão relacionados a maneira como o produto foi projetado. Um produto de baixa qualidade não mostrará segurança e eficácia, independente de quantos testes ou análises forem realizados para verificar sua qualidade. Assim o QbD começa com o reconhecimento de que a qualidade não será garantida com o aumento de número de análises para liberação do produto, mas sim, a qualidade deve ser incorporada ao produto desde o seu processo de fabricação (Yu ET AL., 2014).

O emprego de ferramentas estatísticas, tais como planejamento de experimentos (DoE - Design of Experiments) e metodologia de superfície resposta (RSM - Response Surface Methodology), é fundamental para a determinação do design space. Neste novo conceito, qualidade é construída por meio do conhecimento do produto e do controle dos parâmetros críticos do processo (PINTO, KANEKO, \& PINTO, 2015). 
A ICH Q8 define design space como uma combinação multidimensional das condições relativas aos atributos de qualidade e proporções de excipientes e substâncias ativas, assim como os níveis adequados para cada parâmetro crítico do processo, que garantam a qualidade final do produto (ICH Q8, 2009).

Adicionalmente, a tecnologia analítica de processos (PAT - Process Analytical Technology) tem papel importante no contexto do $\mathrm{QbD}$, uma vez que permite controlar as condições que garantam a qualidade final do produto ao longo do processo produtivo. O PAT pode ser aplicado no processo produtivo de maneira in-line, on-line ou at-line, possibilitando resultados em tempo real e, eventualmente, dispensando as análises finais para verificação de atendimento às especificações (PINTO, KANEKO, \& PINTO, 2015).

As ferramentas estatísticas multivariadas, tais como análise de componentes principais (PCA - Principal Component Analysis) e regressão parcial por mínimos quadrados (PLS - PartialLeast Square Regression), são amplamente utilizadas em quimiometria, por permitirem a avaliação de misturas complexas analisadas por técnicas espectrométricas (UV/Vis, IV, de massas, de ressonância magnética nuclear, dentre outras) (PINTO, KANEKO, \& PINTO, 2015).

Apesar das vantagens associadas ao emprego do $\mathrm{QbD}$ e do PAT no desenvolvimento de novos produtos, encontramos na literatura poucos estudos relatando sua aplicação na indústria farmacêutica e, particularmente, na indústria de cosméticos. Desta forma, o objetivo deste trabalho é aplicar os conceitos do QbD e do PAT no desenvolvimento de sistema conservante para formulações tópicas. 
REVISÃO DE LITERATURA 



\section{REVISÃO DE LITERATURA}

\subsection{Qualidade por Design (QbD)}

O objetivo do Qualidade por Design (QbD) é a concepção de um processo que tenha a capacidade de produzir de forma robusta e segura lotes conformes, sem rejeição ao longo do ciclo de vida do processo e/ou produto. O QbD tem seu embasamento na análise de risco do desenvolvimento farmacêutico, de forma estabelecer um planejamento bem definido de desenvolver formulações e processos de manufatura que garantam a qualidade do produto através da identificação dos pontos críticos (SANGSHETTI, 2014; SALEME, JULIO, \& HUERTAS, 2013).

Os conceitos de QbD no âmbito farmacêutico foram utilizados para melhorar a fabricação de produtos farmacêuticos em termos de abordagem Six-Sigma, que é um sistema de práticas para alcançar a melhoria do processo, o que leva a uma chance significativamente reduzida de produzir lotes fora de especificação. Estes conceitos foram definidos primeiramente por Joseph M. Juran, que acreditava que a qualidade deveria ser projetada para um determinado produto e que a maioria das falhas e problemas de qualidade estava relacionada com o desenvolvimento desse produto. A partir de então a qualidade por teste (Quality by Test - QbT) passou a dar espaço à qualidade por design (Quality by Design - QbD). Juran cita que a idéia de que os problemas referentes a qualidade de um produto estão estritamente relacionados ao modo como ele foi desenvolvido e, portanto a qualidade deve ser controlada a cada etapa do processo, para minimizar as falhas e maximizar a probabilidade do produto alcançar os atributos de qualidade dentro das especificações (BEZERRA, RODRGUES, 2017). 
O número significativo de resultados fora de especificação indica um problema para a indústria farmacêutica (PERAMAN, BHADRAYA, REDDY, 2015). No entanto, muitas vezes os problemas em alcançar o desempenho Six-Sigma não é em função de problemas oriundos do processo de fabricação, mas sim devido a métodos analíticos com baixa de robustez e confiabilidade. Vários autores descrevem a aplicação do conceito de QbD no desenvolvimento de métodos analíticos, conceito denominado Qualidade por Design Analítico (AQbD) (PERAMAN, BHADRAYA, REDDY, 2015; BHUTANI ET AL., 2014).

Ao longo dos estudos e do conhecimento adquirido durante o desenvolvimento farmacêutico, informações são coletadas para a compreensão científica e criação do Design Space (espaço de concepção), para a definição de especificações e controles do produto, facilitando a análise de causa-raiz na gestão dos riscos de qualidade. Os seus princípios têm sido usados para avançar a qualidade durante o processo produtivo, bem como no produto (PINTO, KANEKO, \& PINTO, 2015).

As etapas da QbD são:

- Definir o perfil de qualidade alvo do produto;

- Identificar os Atributos Críticos da Qualidade (CQAs), Atributos críticos de Materiais (CMAs) e os Parâmetros Críticos do Processo (CPPs);

- Planejar e desenvolver o produto e o processo de manufatura;

- Controlar o processo de produção para atingir a qualidade definida de modo consistente. 
O QbD tem como objetivo relacionar os diferentes Atributos Críticos da Qualidade (CQAs) com os Atributos Críticos de Materiais (CMAs) e os Parâmetros Críticos de Processo (CPPs), justificando de forma racional, através de comprovações científicas, os critérios de aceitação propostos para a aprovação e liberação do produto final, evitando o aumento de custos sem comprometer a conformidade do produto. As variações que podem ocorrer durante o processo produtivo, sejam através de matériasprimas, operadores, instalações e equipamentos podem interferir na qualidade do produto e muitas vezes seus efeitos sobre a qualidade final do produto são incompreensíveis. (PINTO, KANEKO, \& PINTO, 2015).

Compreender o processo é a chave para definir o Design Space. O ICH Q8 define o Design Space como uma combinação multidimensional estabelecida dos atributos materiais e/ou parâmetros do processo, assim como suas interações, que garantem a qualidade final do produto. Quando o Design Space está bem definido, o controle do processo produtivo é fácil e a resolução de problemas pode ser antecipada. Uma vez estabelecidos os critérios de aceitação do CQAs, o Design Space pode ser utilizado para definir os critérios de aceitação da variabilidade dos CMAs e CPPs (RATHORE \& WINKLE, 2009).

Tradicionalmente, o desenvolvimento e otimização de produtos farmacêuticos e métodos analíticos são realizados analisando apenas um fator por vez (abordagem OFAT - One-Factor-At-Time). Um dos fatores é alterado dentro de um intervalo apropriado (ou níveis), enquanto os outros fatores são mantidos constantes. Além de exigir muitos experimentos, a abordagem OFAT não permite avaliar a existência de interação entre os fatores, o que pode levar a uma condução inadequada do desenvolvimento e otimização (BEZERRA ET AL., 2008; CANDIOTI ET AL., 2014; POLITIS ET AL., 2017). 
O conceito de QbD iniciou-se devido a quatro fatores importantes (APONTES; DÍAS HUERTA, 2015):

- Disponibilidade de guias que orientavam o desenvolvimento de produtos e a aplicação do conceito de criticidade para classificar as variações do processo;

- A evolução do conceito de vigilância de órgãos sanitários, tornando a própria indústria farmacêutica um órgão regulador interno;

- Utilização de ferramentas estatísticas e de tecnologia informatizada, permitindo análises robustas de dados empíricos;

- Aceitação dos órgãos regulatórios sobre a tomada de decisão com base no risco, tornando possível o controle do processo sem depender das variáveis possíveis no início da fabricação.

Durante o $\mathrm{QbD}$ a ferramenta estatística por Design of Experiments (DoE) é amplamente utilizado para identificar quais os fatores de entrada (CMAs e CPPs) são mais relevantes e como estes fatores de entrada afetam as respostas de interesse (CQAs), auxiliando na concepção do produto e seu processo produtivo (SHIVHARE \& McCREATH, 2010).

A qualidade do produto através da ferramenta de QbD é alcançada ao correlacionar a qualidade do produto ao desempenho esperado, desenhar uma formulação e processo produtivo robusto capaz de gerar lotes com a qualidade esperada. O QbD tem como objetivos (YU ET AL., 2014, GAFANIZ, 2011):

- Alcançar as especificações de qualidade com base em seu desempenho;

- Aumentar a capacidade do processo e reduzir a variabilidade e falhas/defeitos, reforçando a concepção do produto e seu processo, bem como o seu controle. Sendo 
assim, é possível evitar a rejeição de lotes e recolhimento dos produtos que se encontram no mercado;

- Aumentar a eficiência do desenvolvimento e fabricação melhorando a capacidade e velocidade do processo produtivo;

- Melhorar a análise de causa-raiz e gestão de aprovação regulatória;

- Melhorar a rentabilidade e lucratividade da companhia, tornando-a adaptável a mudanças e aumentando sua competitividade no mercado.

Sendo assim, a utilização da QbD abriu novas portas para medição de parâmetros críticos de processo em tempo real, como por exemplo através da tecnologia analítica em processo (Process Analytical Technology - PAT). Esta visão proporcionou novas perspectivas na implantação de tecnologias inovadoras de controle em processo, bem como qualidade de matérias-primas, substâncias ativas, produtos intermediários e do produto acabado (CURTIVO, 2011). 


\subsubsection{Quality Target Product Profile (QTPP)}

Quality target product profile (QTPP) é um resumo das características de qualidade do produto deve ser alcançado para garantir a eficácia e segurança (SANGSHETTI ET AL., 2017; YU ET AL., 2014). Essas características identificam quais os Atributos Críticos de Qualidade (CQAs) que devem ser atendidos para que se possa atingir a qualidade, eficácia e segurança desejada do produto (ICH Q8, 2009).

Apesar do QTPP ser semelhante aas especificações do produto no modelo tradicional, no contexto de QbD esses atributos adquirem um novo significado e função (BEZERRA, RODRIGUES, 2017).

Abaixo estão descritos alguns CQAs correlacionados a produtos farmacêuticos e/ou cosméticos (YU ET AL, 2014; ICH Q8, 2009):

- $\quad$ Finalidade do produto;

- Via de utilização;

- $\quad$ Forma física do produto;

- Claim ou apelo de utilização;

- Material de embalagem;

- Necessidades para atingir o efeito clínico desejado;

- Critérios de qualidade do produto (microbiologia, aspecto, estabilidade em uso).

O QTPP trata das características qualitativas e quantitativas que suportem o desempenho do produto ao ser utilizado, ou seja, é uma predefinição dos Atributos Críticos de Qualidade do produto que são necessárias para garantir a segurança, eficácia até o consumidor final (LIONGERGER ET AL., 2008). Um QTPP bem definido evita desperdício de tempo e de recursos (YU ET AL., 2014). 


\subsubsection{Atributo Críticos de Qualidade (Critical Quality Atributes - CQAs), Parâmetros Críticos de Processo (Critical Process Parameters - CPPs), Atributos Críticos de Materiais (Critical Material Atributes - CMAs)}

Os Atributos Críticos de Qualidade (CQAs) são propriedades ou características biológicas, microbiológicas, físicas ou químicas do produto que apresentam impacto direto no QTPP e devem abranger um limite apropriado, distribuição ou intervalo que garanta a qualidade desejada para o produto. Os Atributos Críticos de Materiais (CMAs) são as características qualitativas e/ou quantitativas dos ativos e excipientes capazes de interferir nos CQAs desejados para se atingir o QTPP. Por outro lado, os Parâmetros Críticos de Processo (CPPs), são parâmetros de cada operação unitária que podem trazer impacto direto nos CQAs. É preciso avaliar quais os CMAs dos ativos e excipientes quem tenham efeito no CQA, para que eles sejam monitorados durante o desenvolvimento do produto e seu ciclo de vida. O mesmo raciocínio deve ser aplicado aos CPPs, de forma a garantir que o processo produtivo opere em condições controladas e que garantam o atendimento aos requisitos da qualidade (YU ET AL, 2014; ICH Q8, 2009; LIONGERGER, 2007). A Figura 01 (adaptada de YU ET AL, 2014) ilustra como os CMAs e CPPs correlacionam-se com os CQAs e, consequentemente com o QTPP. 


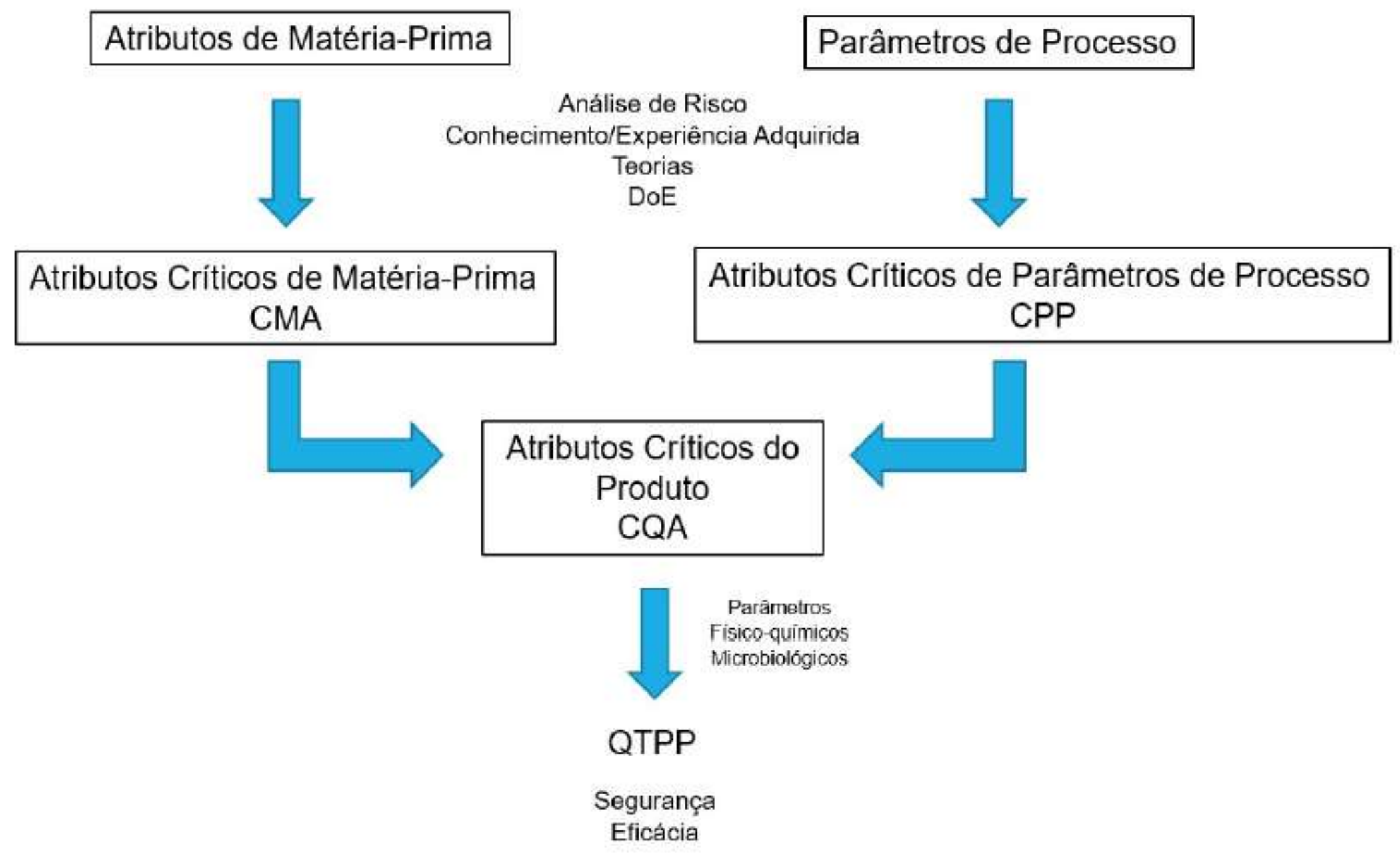

Figura 1. Ilustração da aplicação de Qualidade por Design (QbD) no desenvolvimento de produto e processo (Adaptado YU ET AL, 2014) 


\subsection{Design of Experiments (DoE)}

O DoE é uma técnica utilizada para se planejar experimentos, ou seja, DoE define quais os dados serão coletados, bem como o número de experimentos e as condições em que os mesmos serão realizados, com a finalidade de obter maior precisão estatística, menor custo, resultados mais confiáveis, além economia de dinheiro e tempo (PERES ET AL, 2017).

Sua aplicação durante o desenvolvimento farmacêutico é de suma importância para que uma maior qualidade dos resultados dos testes possa levar a um projeto com desempenho superior, seja em termos de suas características funcionais como também quanto a sua robustez. Em estatística, o DoE abrange toda área de estudos que desenvolve técnicas de planejamento e análise de experimentos. É uma metodologia estruturada para determinar a relação entre os fatores de entrada (xi - variáveis independentes: concentração de conservantes) as quais afetam uma ou mais respostas (yi - variáveis dependentes: microrganismos), por meio de modelo matemático do tipo $\mathrm{y}=\mathrm{f}\left(\mathrm{x}_{\mathrm{i}}\right)$ (FUKUDA ET AL, 2018).

O planejamento de experimentos (DoE) pode fornecer melhores resultados com um pequeno número de experimentos, através de um conjunto de ferramentas estatísticas que inclui planejamentos de triagem e planejamentos de otimização. Os benefícios da utilização de um planejamento experimental é a possibilidade de trabalhar com variáveis independentes (fatores de entrada) e observar como estas afetam a variável dependente (resposta de interesse), sendo possível determinar a relação de causa efeito, e controlar as variáveis com maior eficiência, quando comparado a um experimento tradicional. Através de planejamento de experimentos obtêm-se um espaço de concepção (Design Space) 
seguro para que os CQAs do produto sejam atendidos (BEZERRA ET AL., 2008; CANDIOTIET AL., 2014; POLITIS ET AL., 2017).

Deve-se considerar alguns aspectos para selecionar o melhor planejamento experimental: número de fatores de entrada e interações, validação estatística e de eficácia de cada planejamento, que podem ser subdivididos em duas categorias: planejamentos de triagem e planejamentos de otimização, conforme Tabela 1 (FUKUDA ET AL, 2018).

Tabela 1. Resumo das características dos delineamentos de triagem e otimização, considerando o número de experimentos necessários, o número de níveis de fatores de entrada e os números de fatores a serem estudados.

\begin{tabular}{|c|c|c|c|c|c|}
\hline Aplicação & $\begin{array}{l}\text { Delineamento } \\
\text { experimental }\end{array}$ & Experimentos & Níveis & Fatores & Utilização \\
\hline \multirow[t]{3}{*}{ Triagem } & Plackett-Burman & $\mathrm{N}$ & 2 & $<\mathrm{N}-1$ & Estimar efeitos principais \\
\hline & $\begin{array}{l}\text { Fatorial } \\
\text { fracionado }\end{array}$ & $2^{\mathrm{k}-\mathrm{p}} \operatorname{Res}$ & 2 & $\mathrm{k}>4$ & $\begin{array}{c}\text { Estimar efeitos principais e } \\
\text { interações }\end{array}$ \\
\hline & $\begin{array}{l}\text { Fatorial com } 2 \\
\text { níveis }\end{array}$ & $2^{\mathrm{k}}$ & 2 & $2<\mathrm{k}<5$ & $\begin{array}{l}\text { Estimar efeitos principais e } \\
\text { interações com construção de } \\
\text { superfície resposta }\end{array}$ \\
\hline \multirow[t]{2}{*}{ Otimização } & $\begin{array}{l}\text { Box-Behnken } \\
\text { (BBD) }\end{array}$ & $2 \mathrm{k}(\mathrm{k}-1)+\mathrm{C}$ & 3 & $3<\mathrm{k}<5$ & $\begin{array}{c}\text { Construção de superfície resposta } \\
\text { com termos quadráticos }\end{array}$ \\
\hline & $\begin{array}{l}\text { Compósito central } \\
\text { (CCD) }\end{array}$ & $2^{\mathrm{k}}+2 \mathrm{k}+\mathrm{C}$ & 5 & $2 \mathrm{k}<5$ & $\begin{array}{c}\text { Construção de superfície resposta } \\
\text { com termos quadráticos }\end{array}$ \\
\hline
\end{tabular}

Onde k refere-se ao número de fatores, $\mathrm{p}$ refere-se ao número de geradores escolhidos para fracionar o delineamento e $\mathrm{C}$ refere-se ao número de pontos centrais. 


\subsubsection{Central Composite Design - CCD}

O delineamento de compósito central é constituído por um planejamento fatorial completo de $2^{\mathrm{k}}$, com adição de pontos centrais e pontos axiais, Figura 02 (Fonte: o autor).

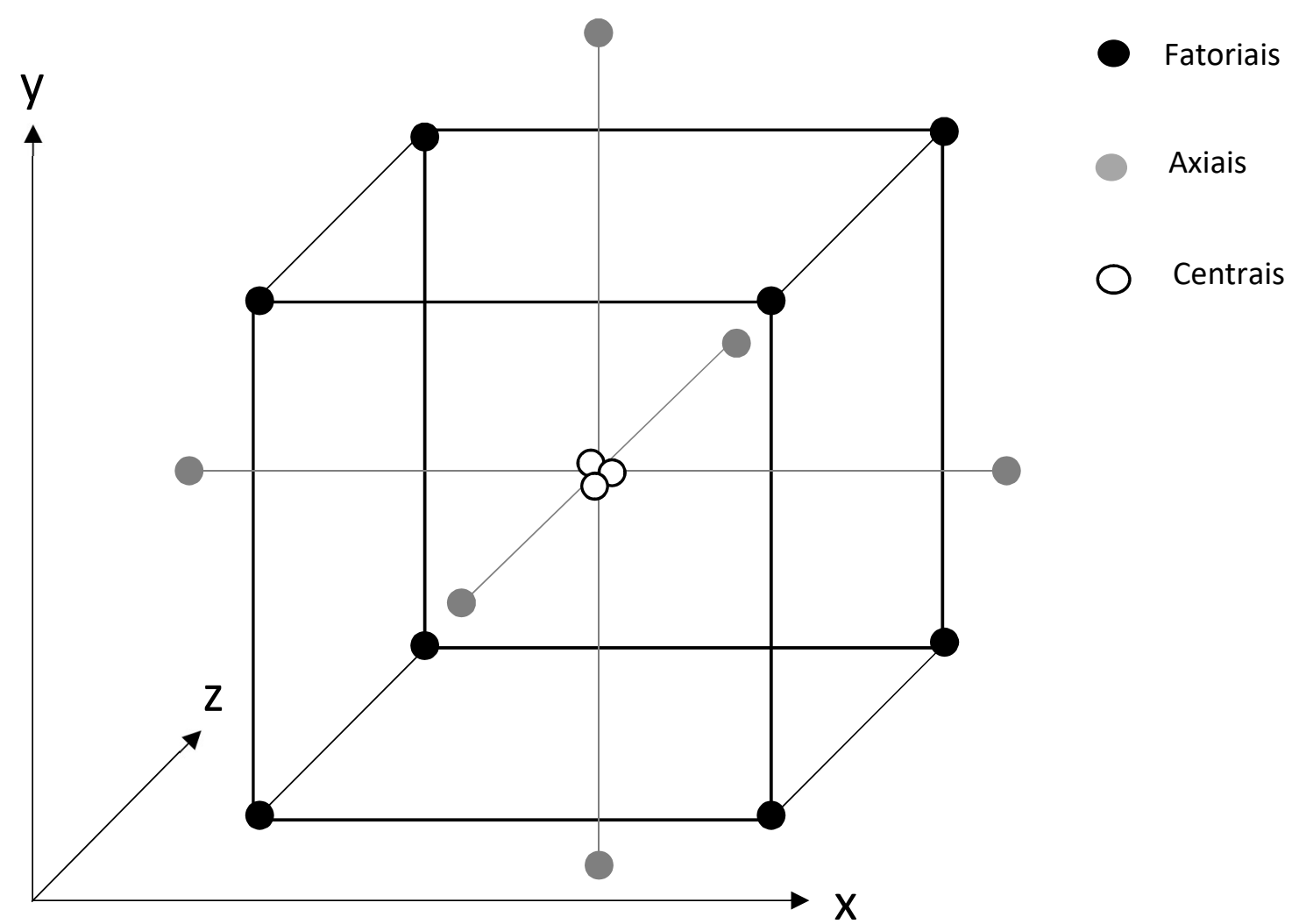

Figura 2. Exemplificação gráfica de pontos Fatoriais, Axiais e Centrais

Os pontos axiais são pontos nos quais todos os parâmetros exceto um são ajustados na média (nível “0”). O valor dos demais parâmetros é dado em termo de distância entre o ponto central e cada amostra fatorial completo normalizada a 1. A distância entre os pontos axiais e o ponto central pode ser escolhida de diferentes formas (CAVAZZUTI, 2013): 
- Quando ajustado em 1, chamado de compósito central circunscrito ou CCC;

- Quando ajustado a $\frac{\sqrt{k}}{k}$ chamado de compósito central faceado ou CCF;

- Se uma amostra como o CCC é desejada, e os limites dos níveis não podem ser violados, o desenho CCC pode ser rebaixado de forma que todas as amostras tenham a distância do ponto central igual ao compósito central circunscrito inscrito ou CCI;

- Se a distância é ajustada para qualquer valor independente se $<\frac{\sqrt{k}}{k}(\mathrm{CCI}),<1$ (pontos axiais dentro da hiperesfera), ou $>1$ (pontos axiais fora da hiperesfera), chama-se de compósito central escalado ou CCS (central aglomerade scaled).

Para $\mathrm{k}$ parametros, $2 \mathrm{k}$ pontos axiais e um ponto central são adicionados ao $2^{\mathrm{k}}$ fatorial completo, aumentando o tamanho de amostra do delineamento de compósito central para $2^{\mathrm{k}}+2 \mathrm{k}+1$ (CAVAZZUTI, 2013).

\subsection{Process Analytical Technology (PAT)}

Process Analytical Technology (PAT) baseia-se em um sistema de análises contínuas e controle durante o processo de fabricação em tempo real ou tempo reduzido, visando garantir a qualidade do produto na fase final do processo através do desempenho dos atributos das matéria-primas e/ou materiais. O ICH tem estimulado a indústria farmacêutica a aumentar as novas pesquisas em tecnologias analíticas ao introduzir o PAT dentro do conceito farmacêutico. Com isso, inovações tecnológicas durante o controle de processo e na qualidade de matérias-primas, produtos semi-acabados e produtos acabados irão controlar o processo produtivo assegurando a qualidade ao produto. O objetivo do PAT é obter informações qualitativas e quantitativas sobre processos, sejam eles 
químicos, físicos (análises reológicas, de superfícies etc.) e/ou biológicos, além de conceitos como instrumentação, amostragem, transporte de amostra, engenharia de fluxo e quimiometria (YU et al, 2014; ICH Q8, 2009).

As informações coletadas durante o processo são utilizadas para controlar e monitorar, além de otimizar a eficiência quanto ao uso de matéria-prima, energia e tempo, contribuindo relativamente para redução do impacto ambiental e sustentabilidade. Diferente da forma convencional, no qual o controle de processo coleta informações inline (quando a amostra não é retirada do processo - automatizado) e on-line (quando a amostra é retirada do processo e pode retornar ao processo - automatizado), o PAT permite planejar e desenvolver processos eficientes controlado através de coleta de dados in-line, on-line e at-line (quando a amostra é retirada e analisada próximo ao processo pelo próprio operador) assegurando a qualidade predefinida no final do processo de fabricação . Os métodos espectroscópicos associados a avanços na área de quimiometria (área que se refere à aplicação de métodos estatísticos e matemáticos a problemas de origem química) constituem as principais ferramentas para a implementação de programas como o PAT (PINTO, KANEKO, \& PINTO, 2015).

A quimiometria utiliza-se de ferramentas estatísticas como o PCA (Principal Components Analysis) e o PLS (Partial Least Squares) que são utilizadas para avaliar dados multivariados relacionando uma ou mais variáveis respostas com diversas variáveis independentes. Tais ferramentas são muito utilizadas em análises espectrofotométricas, como por exemplo, na região do infravermelho, a técnica pode ser utilizada para avaliar o processo em si, além de constituir uma ferramenta importante para mostrar possíveis variações que podem conduzir a um produto fora da especificação. O PCA é utilizado para uma análise exploratório dos resultados, no qual se objetivo é visualizar a estruturas 
dos dados: similaridade entre as amostras, anomalias e reduzir a dimensionalidade dos dados (CARVALHO, 2015; CHALLA, POTUMARTHI, 2012).

O PLS é utilizado para construir um modelo capaz de relacionar as respostas obtidas a partir das amostras e seus parâmetros, sendo seu objetivo principal prever concentrações a partir de novas amostras através do modelo matemático construído (CARVALHO, 2015; CHALLA, POTUMARTHI, 2012).

O método dos mínimos quadrados parciais (Partial Last Square MethodologyPLS) é um método de modelagem de dados, que consiste no ajuste de coeficiente de um modelo função (superfície resposta) para que melhor se ajuste aos dados obtidos (os resultados obtidos através do DoE) (CAVAZZUTI, 2013).

A função deste modelo é $f(x, \beta)$, onde $\beta=\left[\beta_{1, \ldots} \beta_{\mathrm{m}}\right]^{\mathrm{T}}$ é o vetor de $\mathrm{m}$ coeficientes a serem transformados e $\mathrm{x}=\left[\mathrm{x}_{\mathrm{i}, \ldots} \mathrm{x}_{\mathrm{k}}\right]^{\mathrm{T}}$ é o vetor de $\mathrm{k}$ parâmetros dos fatores. O conjunto de dados consiste nos pares $\left(\mathrm{x}_{\mathrm{i}}, \mathrm{y}_{\mathrm{i}}\right)$, onde $\mathrm{x}_{\mathrm{i}}$ são os parâmetros dos fatores de i experimentos cujas variáveis respostas são yi. O PLS escolhe pelas variáveis do coeficiente $\beta_{1}$ dado pela soma dos mínimos quadrados dos resíduos ao ponto do conjunto de dados, onde os resíduos são a diferença entre a resposta experimental e o valor predito pelo algoritmo $\mathrm{x}_{\mathrm{i}}$ do Design Space (CAVAZZUTI, 2013).

A qualidade de uma aproximação no modelo de superfície resposta pode ser estimada pelos parâmetros de regressão. Tais parâmetros são definidos como os valores que recaem dentro de uma faixa de zero a um, e quanto mais próximo de 1, melhor será o modelo (CAVAZZUTI, 2013).

Em uma regressão normal, a medida é a somo dos quadrados dos erros $\left(\mathrm{R}^{2}\right)$, para uma regressão cujos parâmetros foram ajustados de acordo com os termos do DoE e tamanho da amostra com um número de coeficientes $\mathrm{m}$, a medida é referente ao $\mathrm{R}^{2}{ }_{\text {adj }} \mathrm{e}$ 
por definição $\mathrm{R}^{2}$ adj $\leq \mathrm{R}^{2} \leq 1$. Já para estimar a capabilidade preditiva do modelo, $\mathrm{N}$ superfície resposta são construídos onde cada ponto $\mathrm{x}_{\mathrm{i}}$ das amostras do DoE faltante, um novo ponto de $\mathrm{x}_{\mathrm{i}}$ é predito, e avaliado pelo $\mathrm{R}^{2}$ pred. Portanto a ideia principal deste modelo é utilizar os resultados do DoE para criar uma aproximação da variável resposta sobre o Design Space (CAVAZZUTI, 2013).

\subsection{Sistema Conservante}

A partir de 1972, a Federação Internacional Farmacêutica enfatizou a importância da utilização de sistemas conservantes capazes de garantir a estabilidade e segurança de preparações farmacêuticas não estéreis quanto a sua carga microbiana (PINTO, KANEKO, \& PINTO, 2015).

Formas líquidas e semissólidas de base aquosa constituem a grande maioria de preparações estéreis injetáveis, bem como oftálmicas, neste caso, o sistema conservante tem como objetivo, manter a esterilidade inicial em produtos multidoses. Apesar de cosméticos não pertencerem à classe de medicamentos, grande maioria é formulada com base aquosa, portanto, faz-se necessário o uso de sistema conservante adequado (PINTO, KANEKO, \& PINTO, 2015).

De acordo com RDC 162/2001, conservantes são substâncias adicionadas aos produtos de higiene pessoal, cosméticos e perfumes, com a finalidade primária de preservá-los de danos e/ou deteriorações causadas por microrganismos durante sua fabricação e estocagem, bem como proteger o consumidor de contaminação inadvertida durante o uso do produto. Os conservantes são classificados em (PINTO, KANEKO, \& PINTO, 2015): 
- Biocidas: capazes de manter ou reduzir o nível de contaminação por meio da morte microbiana;

- Biostáticos: capazes de manter ou reduzir o nível de contaminação por meio da inibição do crescimento microbiano, sem causar sua morte.

Alguns fatores devem ser levados em consideração durante a escolha do sistema conservante (também conhecidos como blends) adequado para diferentes formulações, sejam elas farmacêuticas e/ou cosméticas, como por exemplo:

- Largo espectro de atividade em ampla faixa de $\mathrm{pH}$ durante a meia-vida do produto;

- Devem ser inodoros, incolores e insípidos;

- Efetividade sobre cepas específicas com número de ATCC, assim como microrganismos da microbiota ambiental encontrados no ambiente fabril;

- Distribuição de forma adequada em sistemas emulsionados;

- Compatibilidade com componentes da fórmula ou da embalagem primária, sem interferir na cor, no sabor ou fragrância;

- Manter sua atividade na presença de outros insumos;

- Não deve decompor sua estrutura durante a esterilização térmica;

- Atóxico e não irritante;

- Custo baixo e/ou aceitável.

No Brasil a RDC 162/2001 regula o uso de conservantes e a concentração permitida para cada classe, tornando obrigatória a declaração de sua concentração centesimal real no produto. Para o mercado brasileiro a RDC permite, em alguns casos, que seja apresentada a fórmula oficial sem o desdobramento total dos seus conservantes, como por exemplo, o do blend de parabenos e fenoxietanol. Se for utilizado até $0,8 \%$, atenderá ao que está estabelecido para a mistura de parabenos e não atingirá o máximo 
permitido para o fenoxietanol. Nesse caso, também não é necessário desdobrar sua composição (RDC 162/2001

\subsubsection{Parabenos}

Os parabenos estão entre os conservantes mais utilizados pela indústria farmacêutica e cosmética, devido ao seu amplo espectro antimicrobiano contra fungos e bactérias, sua compatibilidade com matérias-primas, baixo custo e aceitação regulatória (TAVARES, 2011).

As propriedades antibacterianas dos parabenos são diretamente proporcionais ao comprimento da cadeia do grupo éster, assim, por exemplo, o butilparabeno tem 4 vezes mais capacidade de inibir o crescimento de microrganismos que o etilparabeno. No entanto, ao mesmo tempo em que há o aumento do comprimento da cadeia alquilo, o valor do coeficiente de partição octanol:água sobe, o qual resulta na diminuição da solubilidade em água (BLEDZKA, 2014).

Quanto o mecanismo de ação antimicrobiana dos parabenos, sugere-se que este provoca a disfunção dos processos de transporte da membrana ou pela inibição da síntese de DNA e RNA por sua atividade em enzimas chave, como ATPases e fosfotransferases (VALKOVA, 2001)

Em termos de estrutura química, os parabenos são ésteres (metil, etil, propil, butil, benzil, dentre outros) do ácido p-hidroxidobenzóico (Figura 03) ou seus sais sódicos. Os parabenos são produzidos por esterificação do ácido p-hidroxibenzóico com um álcool adequado na presença de um catalisador (por exemplo, ácido sulfúrico concentrado ou ácido p-toluenossulfônico (LIAO, 2002.). 


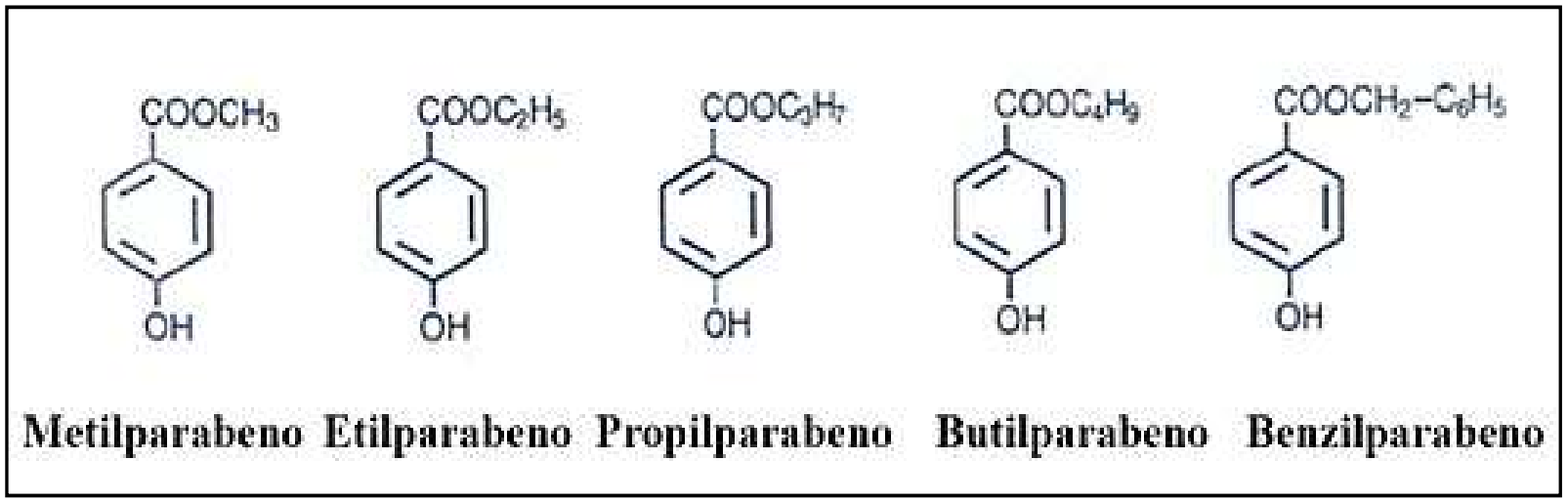

Figura 3. Estrutura química dos parabenos comumente utilizados como conservantes em formulações farmacêuticas e cosméticas.

O metilparabeno e o propilparabeno são os mais utilizados na indústria cosmética e por vezes estão presentes concomitantemente nas formulações farmacêuticas e cosméticas. As principais propriedades físico-química dos parabenos estão apresentadas na Tabela 2 (TAVARES, 2011). 
Tabela 2. Propriedades físico-química dos parabenos comumente utilizados como conservantes em formulações farmacêuticas e cosméticas.

\begin{tabular}{|c|c|c|c|c|c|}
\hline $\begin{array}{c}\text { Nome } \\
\text { Químico }\end{array}$ & Metilparabeno & Etilparabeno & Proprilparabeno & Butilparabeno & Benzilparabeno \\
\hline $\begin{array}{l}\text { Fórmula } \\
\text { molecular }\end{array}$ & $\mathrm{C}_{8} \mathrm{H}_{8} \mathrm{O}_{3}$ & $\mathrm{C}_{9} \mathrm{H}_{10} \mathrm{O}_{3}$ & $\mathrm{C}_{10} \mathrm{H}_{12} \mathrm{O}_{3}$ & $\mathrm{C}_{11} \mathrm{H}_{14} \mathrm{O}_{3}$ & $\mathrm{C}_{14} \mathrm{H}_{12} \mathrm{O}_{3}$ \\
\hline Peso molecular & 152,15 & 166,17 & 180,20 & 194,23 & 229,15 \\
\hline $\begin{array}{l}\text { Aparência / } \\
\text { odor }\end{array}$ & $\begin{array}{l}\text { Cristais } \\
\text { incolores ou pó } \\
\text { cristalino. } \\
\text { Inodoro ou } \\
\text { apresenta odor } \\
\text { característico }\end{array}$ & $\begin{array}{l}\text { Cristal incolor } \\
\text { ou pó branco }\end{array}$ & $\begin{array}{l}\text { Cristais brancos, } \\
\text { inodoro ou } \\
\text { apresenta odor } \\
\text { fraco. }\end{array}$ & $\begin{array}{l}\text { Pequenos } \\
\text { cristais } \\
\text { incolores, pó } \\
\text { cristalino, } \\
\text { sólido } \\
\text { finamente } \\
\text { dividido. }\end{array}$ & - \\
\hline $\begin{array}{l}\text { Ponto de } \\
\text { ebulição }\end{array}$ & $270-280^{\circ} \mathrm{C}$ & $297-298^{\circ} \mathrm{C}$ & - & - & - \\
\hline Ponto de fusão & $131^{\circ} \mathrm{C}$ & $116^{\circ} \mathrm{C}$ & $96-97^{\circ} \mathrm{C}$ & $68-69^{\circ} \mathrm{C}$ & $112^{\circ} \mathrm{C}$ \\
\hline Solubilidade & $\begin{array}{l}\text { Metanol, } \\
\text { etanol, } \\
\text { propilenoglicol, } \\
\text { óleo de } \\
\text { amendoim, } \\
\text { acetona, } \\
\text { benzeno, éter, } \\
\text { tetracloreto de } \\
\text { carbono, } \\
\text { glicerol quente, } \\
\text { água. }\end{array}$ & $\begin{array}{l}\text { Metanol, } \\
\text { etanol, } \\
\text { propilenoglicol, } \\
\text { óleo de } \\
\text { amendoim, } \\
\text { acetona, } \\
\text { benzeno, éter, } \\
\text { tetracloreto de } \\
\text { carbono, } \\
\text { glicerina, água. }\end{array}$ & $\begin{array}{l}\text { Metanol, etanol, } \\
\text { propilenoglicol, } \\
\text { óleo de } \\
\text { amendoim, } \\
\text { acetona, benzeno, } \\
\text { éter, tetracloreto } \\
\text { de carbono, } \\
\text { ligeiramente em } \\
\text { água fervente, } \\
\text { água. }\end{array}$ & $\begin{array}{l}\text { Metanol, } \\
\text { etanol, } \\
\text { propilenoglicol, } \\
\text { óleo de } \\
\text { amendoim, } \\
\text { acetona, } \\
\text { benzeno, éter, } \\
\text { tetracloreto de } \\
\text { carbono, muito } \\
\text { solúvel em } \\
\text { clorofórmio, } \\
\text { glicerina, água. }\end{array}$ & - \\
\hline $\begin{array}{l}\text { Solubilidade } \\
\text { em água }\end{array}$ & $2,13 \pm 0,12$ & $1,16 \pm 0,21$ & $0,37 \pm 0,03$ & $0,158 \pm 0,014$ & - \\
\hline
\end{tabular}


A estabilidade química dos parabenos diminui com o aumento de $\mathrm{pH}$, com hidrólise significante ocorrendo sob $\mathrm{pH}$ fortemente alcalino e temperaturas elevadas, além de serem sensíveis a exposição excessiva a luz. Observa-se alguma redução na atividade com agentes aniônicos, tensoativos não-iônicos, metilcelulose, gelatina, povidone e proteínas. Também são incompatíveis com álcalis e sais de ferro. Sua inativação se dá por meio de diluição e tenso ativo não-iônico, como por exemplo o polissorbato 80 (TAVARES, 2011).

A concentração de uso dos parabenos em formulações cosméticas é acima de $0,4 \%$ para éster único ou até $0,8 \%$ para mistura de ésteres, geralmente $0,2 \%$ de metilparabeno, $0,15 \%$ de etilparabeno, $0,02 \%$ de propil e butilparabeno e $0,006 \%$ de benzilparabeno.

Na Tabela 3 estão apresentadas as concentrações de parabenos encontradas em produtos cosméticos segundo o relatório de segurança da Cosmetic Ingredient Review (CIR, 2008). 
Tabela 3. Concentração de uso dos parabenos comumente utilizados como conservantes em formulações farmacêuticas e cosméticas.

\begin{tabular}{ll}
\hline \multicolumn{1}{c}{ Conservantes } & Concentração (\%) \\
\hline Metilparabeno & De $0,0003 \%$ a $1 \%$, sendo que a concentração de $1 \%$ foi encontrada apenas \\
& em batons. Para os demais produtos, encontrou-se uma concentração máxima \\
& de $0,7 \%$. \\
Etilparabeno & De $0,00002 \%$ a $0,98 \%$, sendo que a concentração de $0,98 \%$ foi encontrada \\
apenas em loções para barbear. Para os demais produtos, encontrou -se uma \\
Propilparabeno & concentração máxima de $0,6 \%$. \\
Isopropilpaabeno & De $0,00002 \%$ a $0,7 \%$. \\
Butilparabeno & De $0,00001 \%$ a $0,3 \%$. \\
Isobutilparabeno & De $0,000007 \%$ a $0,5 \%$. \\
Benzilparabeno & Não encontrado. \\
\hline
\end{tabular}

Apesar de existirem estudos in vivo e in vitro quanto aos efeitos tóxicos ocasionados pelo uso de parabenos, em março de 2012 o Comitê Científico de Segurança ao Consumidor da União Europeia (SCCS) afirmou a segurança dos parabenos em produtos cosméticos. Através do estudo realizado pelo comitê, metilparabeno e etilparabeno foram considerados seguros quando usados até concentração de $0,4 \%$ se isolados ou até $0,8 \%$ se em misturas (blends). Porém, para que propilparabeno e butilparabeno sejam considerados seguros, suas concentrações não devem passar de $0,19 \%$ se isolados e de $0,8 \%$ para misturas (blends). Estes valores foram atualizados em função de estudos sobre a penetração dérmica/metabolismo realizados pelo comitê (SCCS, 2012). 


\subsection{Teste de Eficácia de Conservantes}

Todo produto multidose deve ter a eficácia de seu sistema conservante desafiado. O Teste de eficácia de conservante é o utilizado para avaliar a atividade antimicrobiana de conservantes está descrito em compêndios oficiais como a Farmacopéia Americana, Britânica, Japonesa e Brasileira. O Teste de eficácia de conservante consiste em desafiar um sistema conservante frente a microrganismos padrão, a fim de avaliar a capacidade do sistema conservante em reduzir a carga microbiana ao longo de até 28 dias.

O Teste de Eficácia de Conservantes é um teste que visa assegurar a eficácia dos conservantes adicionados aos produtos farmacêuticos estéreis e não estéreis acondicionados em embalagens de doses múltiplas, assim como para produtos cosméticos e alimentícios (BRASIL., 2010b).

Em tese, todo produto farmacêutico acondicionado em embalagens de doses múltiplas deve ter seu sistema conservante avaliado, durante a fase de desenvolvimento do produto, a fim de garantir a segurança do produto, bem como sua vida útil. O Teste de Eficácia de Conservantes consiste em contaminar o produto com cultura de microrganismos testes, com contagem previamente determinada, de forma que a contaminação final do produto esteja entre $1,0 \times 10^{5} \mathrm{UFC} / \mathrm{g}$ ou $\mathrm{mL}$ e $1,0 \times 10^{6} \mathrm{UFC} / \mathrm{g}$ ou mL. Após a inoculação, alíquotas do produto contaminado são amostradas em intervalos de tempo pré-estabelecidos (usualmente, ao longo de 28 dias) e avaliadas quanto a carga microbiana residual (BRASIL., 2010b e USP, 2019)

Os critérios de aceitação do teste estão diretamente relacionados à categoria do produto descritos nas farmacopeias (BRASIL., 2010b e USP, 2019). 
A atividade conservante é usualmente avaliada frente aos microrganismos Escherichia coli, Pseudomonas aerigonosa, Staphylococcus aureus, Candida albicans e Aspergillus brasiliensis, de acordo com as farmacopéias brasileira e americana (BRASIL., 2010b e USP, 2019). Em alguns casos, também podem ser utilizados microrganismos isolados do ambiente de produção (in house).

\subsubsection{Técnica do Número de Mais Provável}

Os métodos microbiológicos alternativos surgem como uma necessidade para obter respostas mais rápida da presença e enumeração de microrganismos em amostras de produtos farmacêuticos e cosméticos.

A técnica de número de mais prováveis ou técnica dos tubos múltiplos, é um método de análise quantitativo que permite estimar o número de mais provável de microrganismos presente num no determinado produto, através da distribuição de alíquotas de diluições seriadas em tubos de ensaio e/ou microplacas contendo meio de cultura líquido. Desta forma, presume-se que os tubos inoculados com as primeiras diluições apresentarão maior frequência de resultados positivos (presença de crescimento microbiano), enquanto os tubos inoculados com últimas diluições apresentarão maior frequência de resultados negativos (ausência de crescimento microbiano). (BRIONES Jr., 1999)

Se a amostra e as diluições forem homogêneas e se houver um número suficiente de repetições, é possível tratar estatisticamente os resultados e generalizá-los à amostra inicial. O número de tubos positivos em cada diluição serial é utilizado para determinar o 
Número Mais Provável (NMP) presente na amostra, empregando-se tabela estatística (tabela de McGrady) ou equações específicas utilizando MS Excel (BRIONES Jr., 1999). 

OBJETIVOS 



\section{OBJETIVO}

O presente projeto tem por objetivo aplicar os conceitos de QbD e PAT no desenvolvimento de sistemas conservantes para formulações tópicas, utilizando as ferramentas de DOE e RSM para a otimização do sistema conservante e ferramentas de quimiometria e espectrofotometria para a avaliação em tempo reduzido. Dentre os objetivos específicos destacam-se:

- Avaliar a eficácia dos sistemas conservantes frente a microrganismos padrão, empregando a técnica do número mais provável em microplacas;

- Determinar a região de Design Space considerando a otimização da eficácia do sistema conservante frente aos 3 microrganismos padrão testados simultaneamente, empregando delineamento de compósito central;

- Desenvolver método espectrométrico, em associação com técnicas quimiométricas (ferramentas PCA e PLS), para a avaliação da eficácia do sistema conservante em tempo reduzido. 

MATERIAIS E MÉTODOS 



\section{MATERIAIS E MÉTODOS}

\subsection{Sistema Conservante}

Para o presente projeto foram utilizadas 15 formulações preparadas a base de creme lanette ${ }^{\circledR}$ com três conservantes da classe dos ésteres de ácido p-hidroxibenzóico, os parabenos, sendo eles: metilparabeno, propilparabeno e isobutilparabeno, em concentrações de $0,000 \%, 0,010 \%, 0,025 \%, 0,040 \% 0,050 \%(\mathrm{p} / \mathrm{v})$.

\subsubsection{Obtenção e padronização de suspensão microbiana}

Para realização dos ensaios do presente projeto foram utilizados os microrganismos padrão: Escherichia coli (ATCC 8739), Staphylococcus aureus (ATCC 6538) e Candida albicans (ATCC 10231), descritos em compêndios oficiais, derivados de cepas padrão ATCC (American Type Culture Collection). Os microrganismos foram mantidos sobre superfície de Ágar Triptona de Soja (TSA) em tubo de ensaio, não ultrapassando a $5^{\mathrm{a}}$ geração, até o momento do uso. (UNITED STATES PHARMACOPEIA, 2019).

A partir de uma cultura de cerca de $24 \mathrm{~h}$ de incubação a $32 \pm 2,5^{\circ} \mathrm{C}$ em meio Agar Triptona de Soja (TSA) para Escherichia coli (ATCC 8739), Staphylococcus aureus (ATCC 6538) e em meio Ágar Sabouraud-dextrose (SDA) a $22 \pm 2,5^{\circ} \mathrm{C}$ durante 24 horas para Candida albicans (ATCC 10231), foi transferido com o auxílio de loop estéril uma quantidade suficiente do microrganismo para um tubo de ensaio contendo $3 \mathrm{~mL}$ solução salina $0,9 \%(\mathrm{p} / \mathrm{v})$ estéril. Em seguida, a turbidez das suspensões microbianas foi ajustada 
a 0,30 de absorbância em comprimento de onda e $580 \mathrm{~nm}$, com o auxílio do equipamento Pocket Colorimeter ${ }^{\circledR}$.

\subsubsection{Preparo da amostra}

Alíquotas de $10 \mathrm{~g}$ do creme foram inoculadas com $100 \mu \mathrm{l}$ de cada suspensão de forma que a obter contaminação final do produto de cerca de $1,0 \times 10^{6} \mathrm{UFC} / \mathrm{g}$ para bactérias e $1,0 \times 10^{5} \mathrm{UFC} / \mathrm{g}$ para levedura. A carga microbiana foi avaliada nos tempos: Inicial (T0), e após 1h (T1), 2hs (T2), 4hs (T3), 24hs (T4), 48 hs (T5) e 72 hs (T6).

\subsubsection{Avaliação da eficácia dos conservantes através de microdiluição em caldo}

Nos intervalos de tempo pré-determinados, Alíquotas de $1 \mathrm{~g}$ do creme base inoculado foi transferido para um tubos contendo $10 \mathrm{ml}$ de caldo Soja Tripticaseína (TSB) previamente acrescido com de $4 \%(\mathrm{p} / \mathrm{v})$ de Polissorbato 20 e $0,5 \%(\mathrm{p} / \mathrm{v})$ de lecitina de soja e a fim de se obter a neutralização do sistema conservante. A homogeneização foi efetuada por meio de agitação em agitador tipo vórtex por 30 segundos.

A contagem dos microrganismos sobreviventes foi realizada através de diluições seriadas, diluindo $100 \mu \mathrm{l}$ da suspensão em $1 \mathrm{ml}$ de caldo Soja Tripticaseína (TSB), sucessivamente, foi transferido $200 \mu 1$ de cada diluição para microplaca. O procedimento foi realizado em triplicada para garantir a repetibilidade do ensaio. O esquema de distribuição das diluições $\left(10^{-2}\right.$ a $\left.10^{-6}\right)$ para as alíquotas testadas imediatamente após a inoculação (T0), e após 1h (T1), 2hs (T2), 4hs (T3), 24hs (T4), 48 hs (T5) e 72 hs (T6) 
após as formulações terem sido inoculadas com Candida albicans (ATCC 10232), Escherichia coli (ATCC 8739), e Staphylococcus aureus (ATCC 6538) está apresentado na Figura 04.

As microplacas foram incubadas a $32,5 \pm 2,5^{\circ} \mathrm{C}$ para bactérias e a $22,5 \pm 2,5^{\circ} \mathrm{C}$ para levedura, sob agitação.

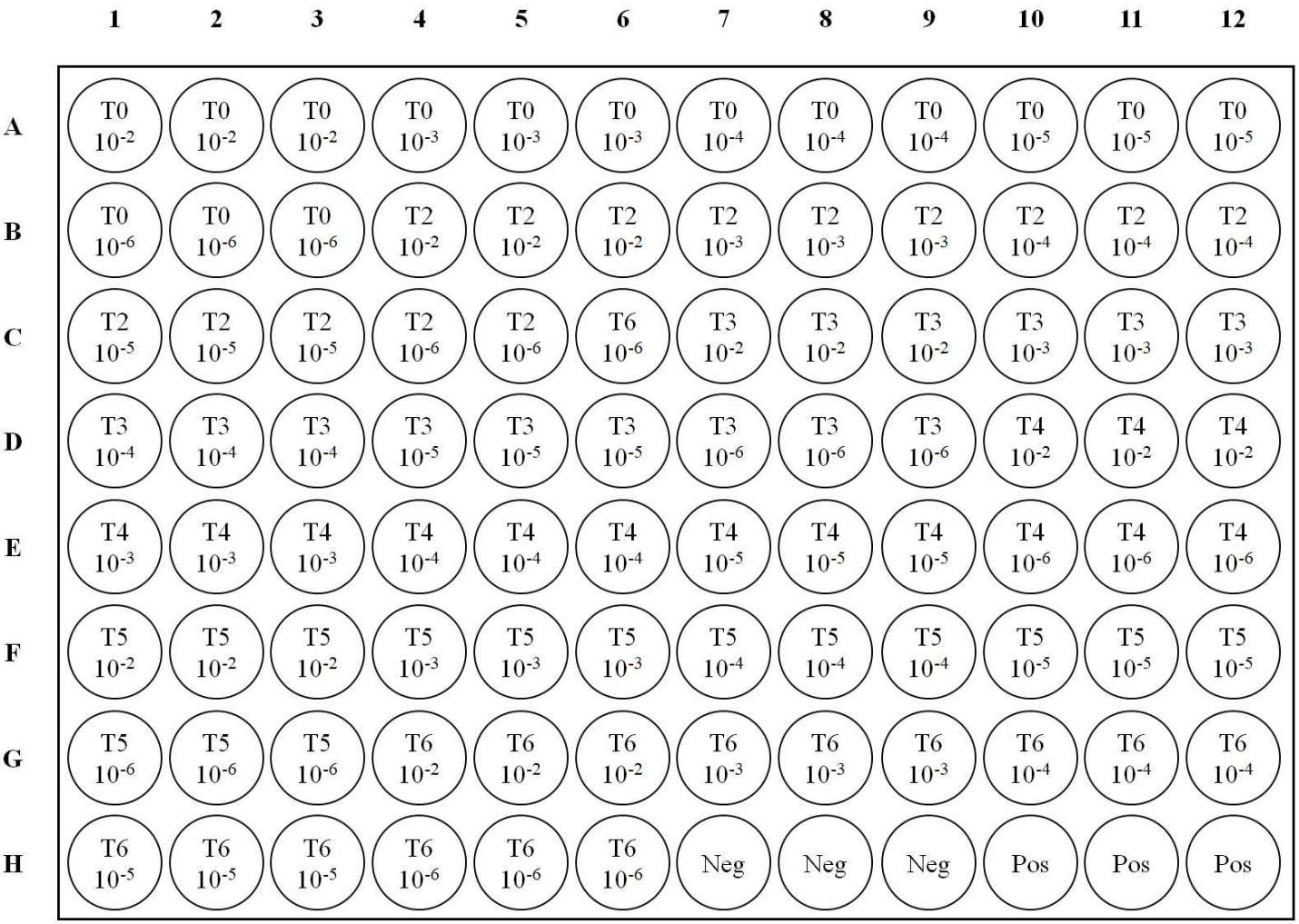

Figura 4. Esquema de distribuição das diluições $\left(10^{-2}\right.$ a $\left.10^{-6}\right)$ para as alíquotas testadas imediatamente após a incubação inicial (T0), e após 1h (T1), 2hs (T2), 4hs (T3), 24hs (T4), 48 hs (T5) e 72 hs (T6) após as formulações terem sido inoculadas com Candida albicans (ATCC 10232), Escherichia coli (ATCC 8739), e Staphylococcus aureus (ATCC 6538). 


\subsubsection{Avaliação da atividade inibitória dos agentes neutralizantes e toxicidade}

Foram transferidas para placas de Petri alíquotas de $1 \mathrm{~mL}$ das diluições 1:10 e 100 $\mu \mathrm{L}$ da suspensão microbiana padronizada contendo concentração de 10 a $100 \mathrm{UFC} / \mathrm{mL}$, sendo adicionado, aproximadamente, $15 \mathrm{~mL}$ de Agar Triptona de Soja (TSA) para bactérias. Isso também foi realizado para os fungos empregando-se Agar Sabourauddextrose (SDA). As placas foram incubadas a $32,5 \pm 2,5^{\circ} \mathrm{C}$ por 48 horas para bactérias e a $22,5 \pm 2,5^{\circ} \mathrm{C}$ por 5 dias para os fungos.

$\mathrm{O}$ agente conservante foi considerado inativado e sem toxicidade ao microrganismo, quando houve recuperação de $50 \%$ a $200 \%$ da contagem inicial dos microrganismos (UNITED STATES PHARMACOPEIA, 2019).

\subsection{Otimização da avaliação da eficácia de conservantes empregando QbD}

Para otimizar o sistema de conservação microbiana de formulações cosméticas as concentrações dos conservantes a serem desafiados foram estabelecidas conforme o planejamento de compósito central (CCD - Central Composite Design) (SHIVHARE \& McCREATH, 2010). Para o projeto foram realizados três conjuntos distintos de ensaios para avaliar a concentração ideal a fim de se obter um sistema conservante eficaz. Sendo eles: o conjunto de pontos fatoriais, o conjunto de pontos axiais e o conjunto de pontos centrais, conforme descrito na Tabela 4. 
Tabela 4. Concentração de conservantes empregados no preparo das formulações, de acordo com o planejamento de experimentos adotado.

\begin{tabular}{|c|c|c|c|c|}
\hline Formulação & & & & \\
\hline & Pontos & Metilparabeno (\%) & Propilparabeno (\%) & Isobutilparabeno (\%) \\
\hline 1 & Fatorial & 0,01 & 0,01 & 0,01 \\
\hline 2 & Fatorial & 0,04 & 0,01 & 0,01 \\
\hline 3 & Fatorial & 0,01 & 0,04 & 0,01 \\
\hline 4 & Fatorial & 0,04 & 0,04 & 0,01 \\
\hline 5 & Fatorial & 0,01 & 0,01 & 0,04 \\
\hline 6 & Fatorial & 0,04 & 0,01 & 0,04 \\
\hline 7 & Fatorial & 0,01 & 0,04 & 0,04 \\
\hline 8 & Fatorial & 0,04 & 0,04 & 0,04 \\
\hline 9 & Axial & 0,00 & 0,025 & 0,025 \\
\hline 10 & Axial & 0,05 & 0,025 & 0,025 \\
\hline 11 & Axial & 0,025 & 0,00 & 0,025 \\
\hline 12 & Axial & 0,025 & 0,05 & 0,025 \\
\hline 13 & Axial & 0,025 & 0,025 & 0,00 \\
\hline 14 & Axial & 0,025 & 0,025 & 0,05 \\
\hline 15 & Central & 0,025 & 0,025 & 0,025 \\
\hline
\end{tabular}

O planejamento de compósito central (CCD) foi utilizado para determinação da região de Design Space, com o objetivo de fornecer gráficos de contorno que ilustram a forma pela qual as concentrações de conservantes influenciam na eficácia do sistema de conservação microbiana em formulações cosméticas. Os níveis dos fatores são vistos como pontos no espaço de fatores (muitas vezes multidimensional) no qual a resposta foi registrada. 
Assim, foi determinada à região de Design Space considerando a otimização da eficácia do sistema conservante frente aos 3 microrganismos simultaneamente.

\subsection{Desenvolvimento de método espectrométrico empregando PAT}

Para cada sistema conservante, de acordo com o planejamento de composto central (CCD), foram realizadas análises em equipamento espectrométrico no infravermelho equipado com o aparato ATR (Attenuated Total Reflectance), na região de comprimento de onda entre 400 a $4000 \mathrm{~cm}^{-1}$.

Os espectros obtidos para cada formulação foram avaliados empregando a análise de componentes principais (PCA), cujo objetivo é verificar o nível e tipo de correlações existentes entre as respostas das diferentes concentrações de conservantes, e também através da regressão parcial por mínimos quadrados (PLS) com a finalidade de estabelecer modelo de regressão que permita quantificar as concentrações de conservantes e assim, predizer a eficácia do sistema conservante. Os espectros foram tratados quanto a derivação ( $1^{\mathrm{a}}$ e $2^{\mathrm{a}}$ ordem) e suavização (utilizando-se o método das médias móveis), de forma a permitir melhor ajuste do modelo.

Os ajustes dos modelos de predição foram avaliados com base nos coeficientes de determinação $\left(\mathrm{R}^{2}\right)$ e quanto a sua capacidade de predição $\left(\mathrm{R}^{2}\right.$ de predição, obtido a partir do PRESS). Foram utilizadas abordagens de validação interna (validação cruzada) e validação externa (conjuntos de dados de calibração e validação independentes). As análises foram realizadas utilizando-se o software MinitabTM $17^{\circledR}$. 
Os resultados da análise multivariada serviram de base para o desenvolvimento do método espectrométrico empregando o conceito PAT. 

RESULTADOS E DISCUSSÃO 



\section{RESULTADOS E DISCUSSÃO}

Conservantes são substâncias químicas cuja função é inibir o crescimento de microrganismos (bactérias, fungos e leveduras), garantindo a estabilidade e a segurança de preparações farmacêuticas não estéreis por toda sua vida útil. Não é função do conservante compensar a falta de boas práticas durante o processo de fabricação, mas sim oferecer um produto livre de contaminação microbiana, mesmo que o consumidor introduza inadvertidamente uma carga microbiana durante a utilização do produto (PINTO, KANEKO, \& PINTO, 2015).

A escolha do conservante deve levar em consideração sua distribuição em sistemas emulsionados, seu espectro de atividade na faixa de $\mathrm{pH}$ do produto, sua compatibilidade com outros componentes da formulação e a manutenção de sua atividade antimicrobiana na presença de outros insumos da formulação, além de sua estabilidade durante a esterilização térmica (PINTO, KANEKO, \& PINTO, 2015).

A atividade de água deve ser avaliada para definir a susceptibilidade do produto à contaminação por bactérias, fungos ou leveduras. Em geral, cremes e loções exigem do conservante tanto atividade bacteriostática quanto fungiostática. As propriedades físicoquímicas dos conservantes devem ser avaliadas para prever futuras incompatibilidades químicas ou até mesmo a inativação do conservante. Também deve ser considerada a regulamentação quanto ao uso de substâncias conservantes permitidas (BRASIL, 2001). 
Para a avaliação da inativação do sistema conservante em função da diluição e agentes neutralizantes, as formulações avaliadas foram as F8, F10, F12, e F15, sendo as que possuem concentração maior de conservante.

O procedimento de inativação do sistema conservante mostrou-se efetivo, apresentando resultados de recuperação microbiana entre 50 e $200 \%$, conforme resultados apresentados na tabela 05 e 06.

Tabela 5. Controle positivo para inativação do sistema conservante

\begin{tabular}{ccc}
\hline Candida albicans & Escherichi coli & Staphylococcus aureus \\
\hline Média UFC/mL & Média UFC/mL & Média UFC/mL \\
\hline 22 & 39 & 27 \\
\hline
\end{tabular}

Tabela 6. Recuperação microbiana frente a inativação do sistema conservante.

\begin{tabular}{ccccc}
\hline & & Candida albicans & Escherichi coli & Staphylococcus aureus \\
\cline { 3 - 5 } Formulação & Diluição & Média UFC/mL & Média UFC/mL & Média UFC/mL \\
\hline 8 & $1 / 10$ & 21 & 36 & 21 \\
8 & $1 / 100$ & 25 & 31 & 23 \\
10 & $1 / 10$ & 17 & 37 & 24 \\
10 & $1 / 100$ & 20 & 39 & 25 \\
12 & $1 / 10$ & 21 & 41 & 23 \\
12 & $1 / 100$ & 24 & 30 & 29 \\
14 & $1 / 10$ & 20 & 44 & 24 \\
14 & $1 / 100$ & 18 & 35 & 24 \\
\hline
\end{tabular}

Os resultados de recuperação microbiana frente a inativação do sistema conservante, para cada formulação nas diluições 1/10 e 1/100 foram: 
- F8: $95 \%$ e $119 \%$, respectivamente para $1 / 10$ e 1/100 para Candida albicans; $92 \%$ e $70 \%$, respectivamente para $1 / 10$ e $1 / 100$ para Escherichi coli e $78 \%$ e $85 \%$, respectivamente para 1/10 e 1/100 para Staphylococcus aureus;

- F10: $77 \%$ e 91\%, respectivamente para 1/10 e 1/100 para Candida albicans; $95 \%$ e $100 \%$, respectivamente para $1 / 10$ e $1 / 100$ para Escherichi coli e $89 \%$ e $93 \%$, respectivamente para 1/10 e 1/100 para Staphylococcus aureus;

- F12: $95 \%$ e $109 \%$, respectivamente para 1/10 e 1/100 para Candida albicans; $105 \%$ e $77 \%$, respectivamente para 1/10 e 1/100 para Escherichi coli e $85 \%$ e 107\%, respectivamente para 1/10 e 1/100 para Staphylococcus aureus;

- F14: $91 \%$ e $82 \%$, respectivamente para $1 / 10$ e 1/100 para Candida albicans; $113 \%$ e $90 \%$, respectivamente para $1 / 10$ e $1 / 100$ para Escherichi coli e $89 \%$ e $89 \%$, respectivamente para 1/10 e 1/100 para Staphylococcus aureus.

Os gráficos de redução da carga microbiana ao longo do tempo para os micrororganismo Candida albicans (ATCC 10231), Escherichi coli (ATCC 8739) e Staphylococcus aureus (ATCC 6538) estão apresentados nas Figuras 05, Figura 06 e Figura 07, respectivamente. 
F1

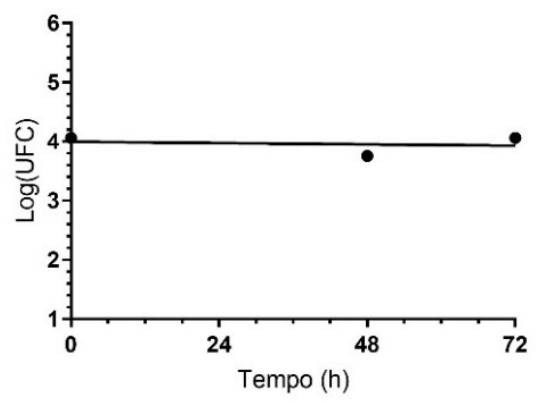

F3

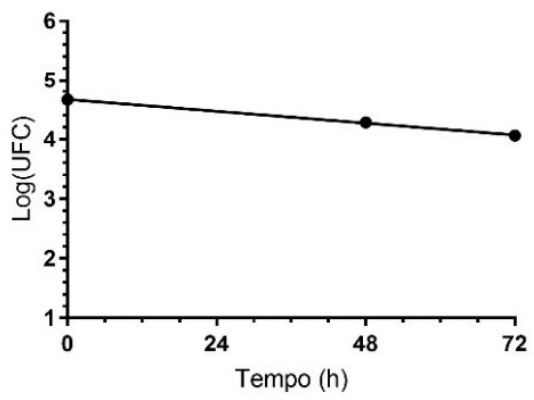

F5

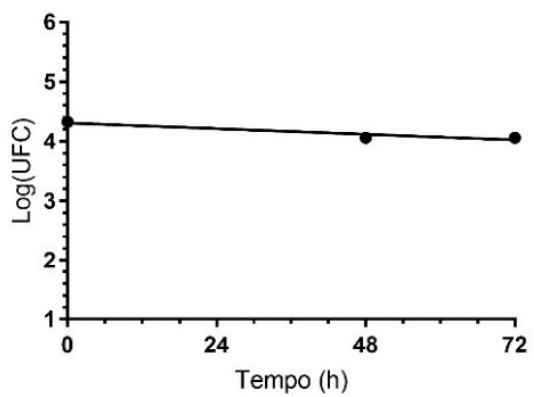

F7

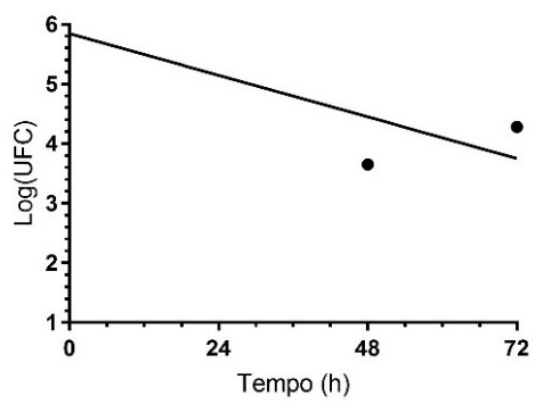

F2

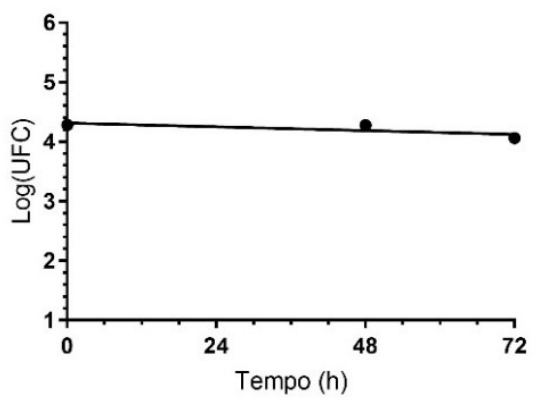

F4

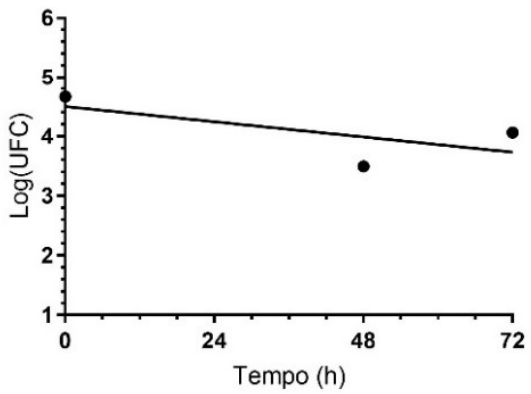

F6

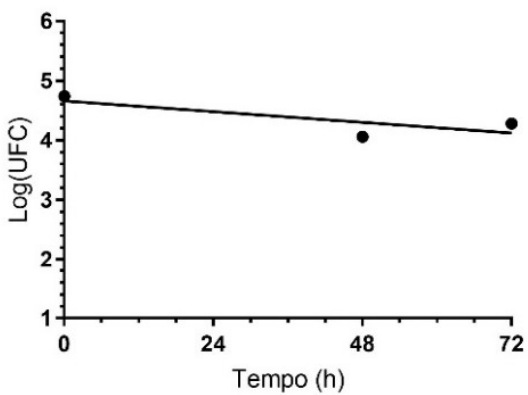

F8

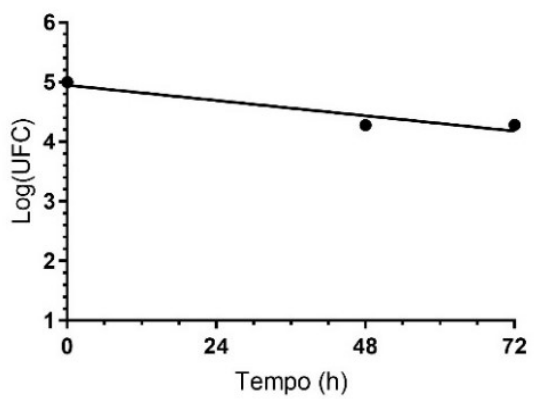

Figura 5. Gráficos de redução da carga microbiana ao longo do tempo para Candida albicans nas formulações de F1 a F8. 
F1

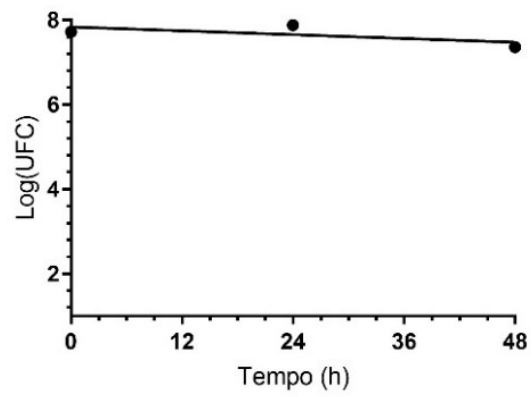

F3

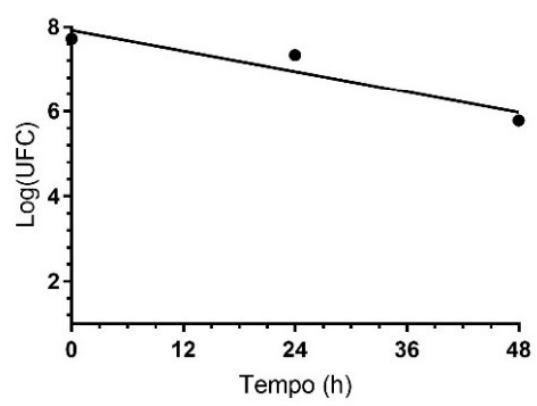

F5

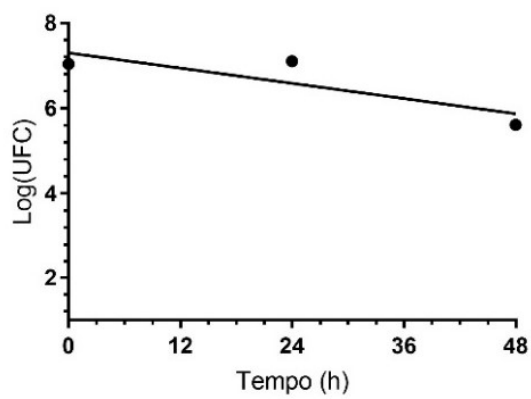

F7

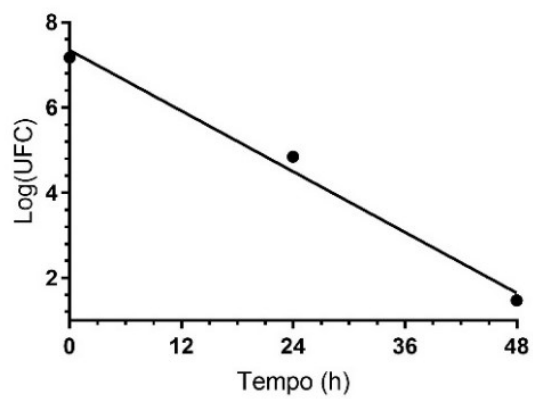

F2

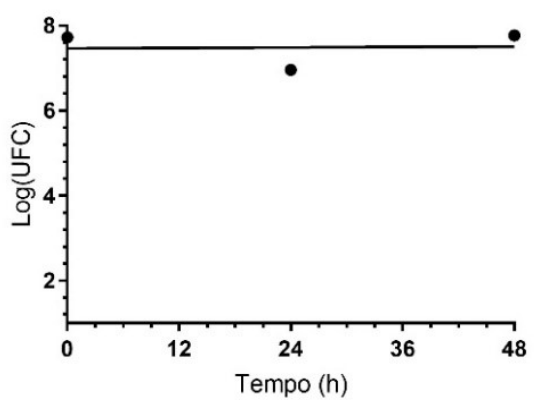

F4

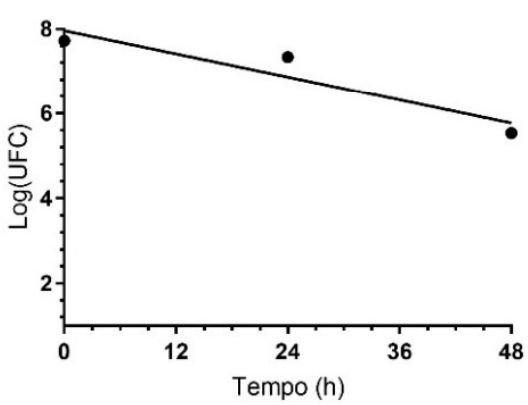

F6

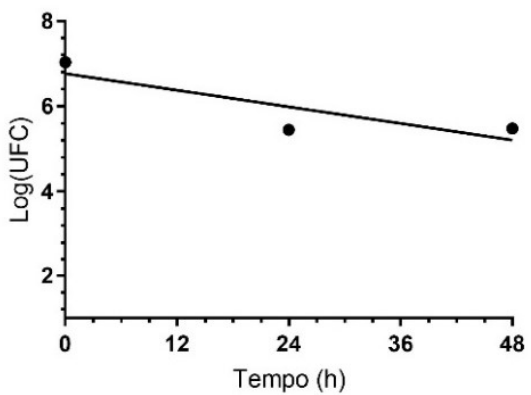

F8

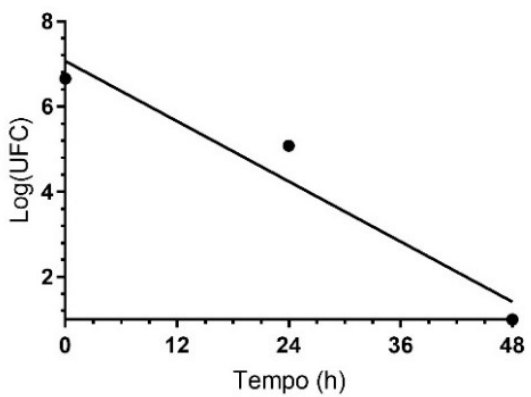

Figura 6. Gráficos de redução da carga microbiana ao longo do tempo para Escherichia coli nas formulações de F1 a F8. 
F1

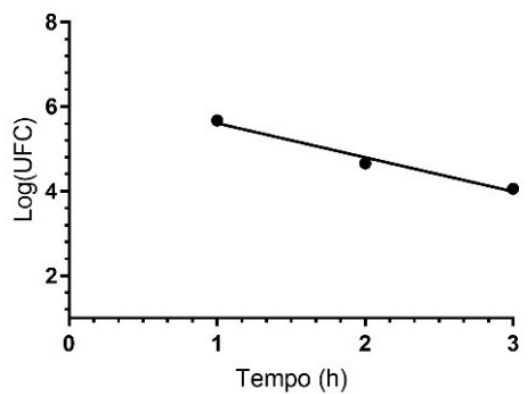

F3

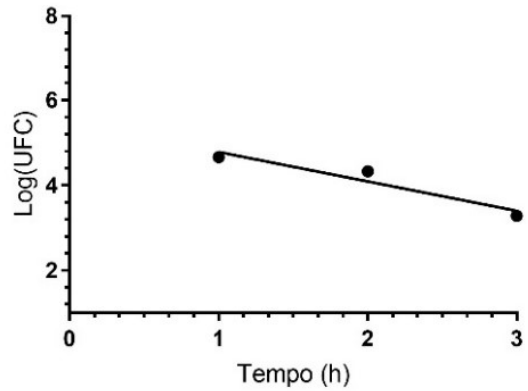

F5

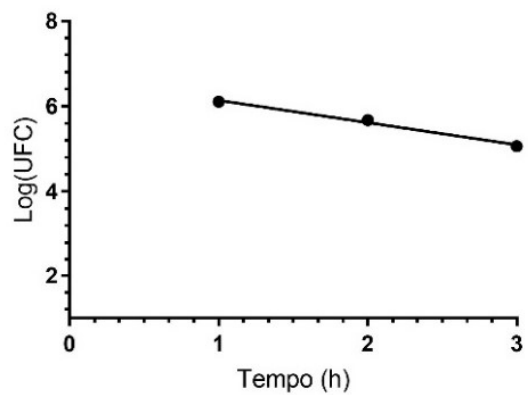

F7

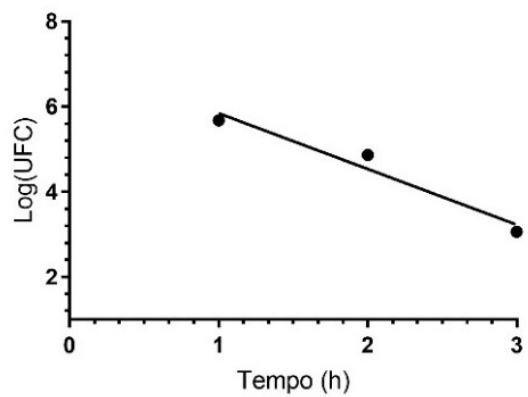

F2

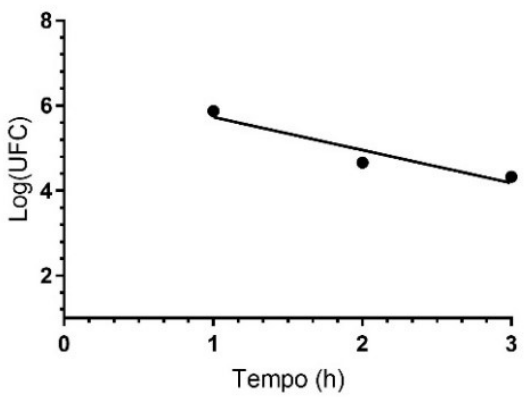

F4

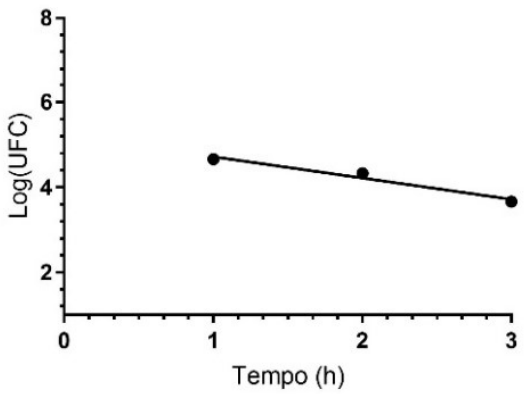

F6

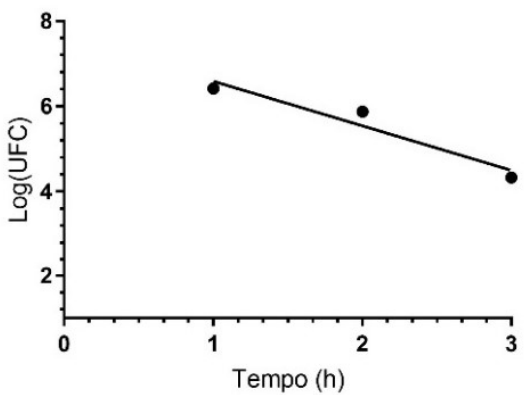

F8

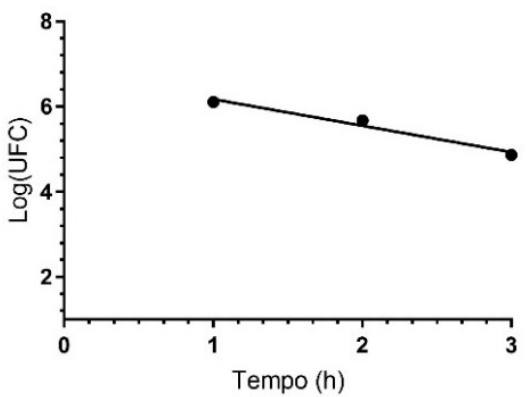

Figura 7. Gráficos de redução da carga microbiana ao longo do tempo para Staphylococcus aureus nas formulações de F1 a F8. 
Com base nestes resultados de redução da carga microbiana ao longo do tempo, foram determinadas as curvas de morte microbiana, sendo que as inclinações ("slopes”) das curvas para cada microrganismo (Candida albicans - Y1, Escherichi coli - Y2, e Staphylococcus aureus - Y3) foram relacionados com as concentrações de conservantes (metilparabeno - X1, propilparabeno $-\mathrm{X} 2$, e isobutilparabeno $-\mathrm{X} 3$ ). Os valores de “slopes” obtidos estão apresentados na Tabela 7.

Tabela 7. Resultados dos "slopes" obtidos a partir das curvas de morte microbiana de Candida albicans (Y1), Escherichia coli (Y2) e Staphylococcus aureus (Y3), em função das concentrações de metilparabeno (X1), propilparabeno (X2) e isobutilparabeno (X3).

\begin{tabular}{ccccccc}
\hline \multirow{2}{*}{ Formulações } & \multicolumn{3}{c}{ Variáveis independentes } & \multicolumn{3}{c}{ Variáveis dependentes } \\
\cline { 2 - 7 } & $\mathbf{X 1}$ & $\mathbf{X 2}$ & $\mathbf{X 3}$ & Y1 & Y2 & Y3 \\
\hline 1 & 0,01 & 0,01 & 0,01 & $-0,0036$ & $-0,022$ & $-0,507$ \\
2 & 0,04 & 0,01 & 0,01 & $-0,0045$ & $-0,032$ & $-0,775$ \\
3 & 0,01 & 0,04 & 0,01 & $-0,0083$ & $-0,041$ & $-0,691$ \\
4 & 0,04 & 0,04 & 0,01 & $-0,0157$ & $-0,046$ & $-0,931$ \\
5 & 0,01 & 0,01 & 0,04 & $-0,0039$ & $-0,062$ & $-0,554$ \\
6 & 0,04 & 0,01 & 0,04 & $-0,0094$ & $-0,066$ & $-0,959$ \\
7 & 0,01 & 0,04 & 0,04 & $-0,0347$ & $-0,119$ & $-1,308$ \\
8 & 0,04 & 0,04 & 0,04 & $-0,0374$ & $-0,118$ & $-1,554$ \\
\hline
\end{tabular}


Inicialmente foram realizados os testes de eficácia do sistema conservantes para as formulações 1 a 8 , correspondentes aos pontos fatorais do CCD. Os resultados de análise de variância (ANOVA) do planejamento de compósito central (CCD) das formulações contendo diferentes concentrações de parabenos estão apresentados na Tabela 8. As equações de regressão, assim como os coeficientes de determinação estão apresentados na Tabela 9.

Tabela 8. Resultados de ANOVA para os "slopes" obtidos a partir das curvas de morte microbiana de Candida albicans (Y1), Escherichia coli (Y2) e Staphylococcus aureus (Y3), em função das concentrações de metilparabeno (X1), propilparabeno (X2) e isobutilparabeno (X3).

\begin{tabular}{|c|c|c|c|c|c|c|c|c|c|}
\hline \multirow{2}{*}{ Fonte } & \multicolumn{3}{|c|}{ Y1 } & \multicolumn{3}{|c|}{ Y2 } & \multicolumn{3}{|c|}{ Y3 } \\
\hline & gl & SQ & $\mathbf{P}$ & gl & SQ & $\mathbf{P}$ & gl & SQ & $\mathbf{P}$ \\
\hline Regressão & 4 & 0,001315 & 0,002 & 4 & 0,009570 & 0,000 & 4 & 0,922744 & 0,002 \\
\hline $\mathrm{X} 1$ & 1 & 0,000034 & 0,065 & 1 & 0,000043 & 0,136 & 1 & 0,168182 & 0,005 \\
\hline $\mathrm{X} 2$ & 1 & 0,00000 & 0,800 & 1 & 0,000008 & 0,458 & 1 & 0,000002 & 0,981 \\
\hline $\mathrm{X} 3$ & 1 & 0,00011 & 0,206 & 1 & 0,000327 & 0,011 & 1 & 0,001436 & 0,538 \\
\hline $\mathrm{X} 2 * \mathrm{X} 3$ & 1 & 0,000230 & 0,005 & 1 & 0,000711 & 0,004 & 1 & 0,127119 & 0,007 \\
\hline Erro & 3 & 0,000013 & & 3 & 0,000032 & & 3 & 0,008985 & \\
\hline Total & 7 & 0,001327 & & 7 & 0,009601 & & 7 & 0,931729 & \\
\hline
\end{tabular}


Tabela 9. Equações de regressão e coeficientes de determinação das velocidades de morte das formulações contendo diferentes concentrações de metilparabeno, propilparabeno e isobutilparabeno.

\begin{tabular}{lccc}
\hline \multicolumn{1}{c}{ Equações de regressão } & R2 & R2adj & R2pred \\
\hline $\mathrm{Y} 1=0,00050-0,1383 \mathrm{X} 1-0,0260 \times 2+0,1511 \mathrm{X} 3-0,23,82$ & $99,05 \%$ & $97,78 \%$ & $93,24 \%$ \\
$\mathrm{X} 2 * \mathrm{X} 3$ & & & \\
$\mathrm{Y} 2=-0,00914-0,1548 \mathrm{X} 1-0,126 \mathrm{X} 2-0,829 \mathrm{X} 3-41,89$ & $99,67 \%$ & $99,23 \%$ & $97,65 \%$ \\
$\mathrm{X} 2 * \mathrm{X} 3$ & & & \\
$\mathrm{Y} 3=-0,3599-9,67 \mathrm{X} 1-0,07 \mathrm{X} 2+1,74 \mathrm{X} 3-560,2 \mathrm{X} 2 * \mathrm{X} 3$ & $99,04 \%$ & $97,75 \%$ & $93,14 \%$ \\
\hline
\end{tabular}

Os gráficos 3D das velocidades de morte para os microrganismos Candida albicans (ATCC 10231), Escherichi coli (ATCC 8739) e Staphylococcus aureus (ATCC 6538) estão apresentados nas Figuras 08, Figura 09 e Figura 10, respectivamente. 

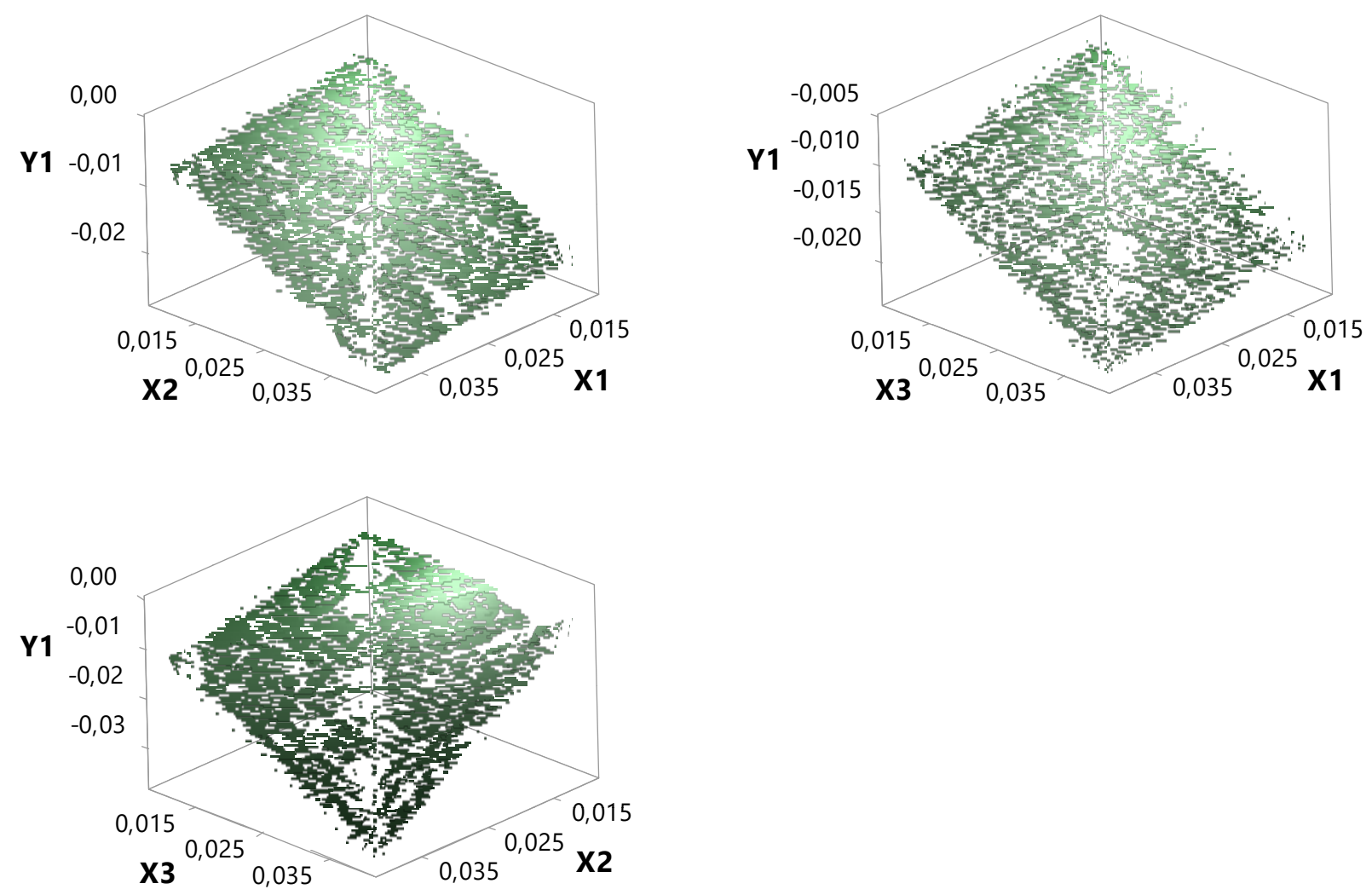

Figura 8. Gráficos 3D dos "slopes" para Candida albicans (Y1) em função das concentrações de metilparabeno (X1), propilparabeno (X2) e isobutilparabeno (X3). Valores fixados em X1 $=0,025 \%, \mathrm{X} 2=0,025 \%$ e X3 $=0,025 \%$. 

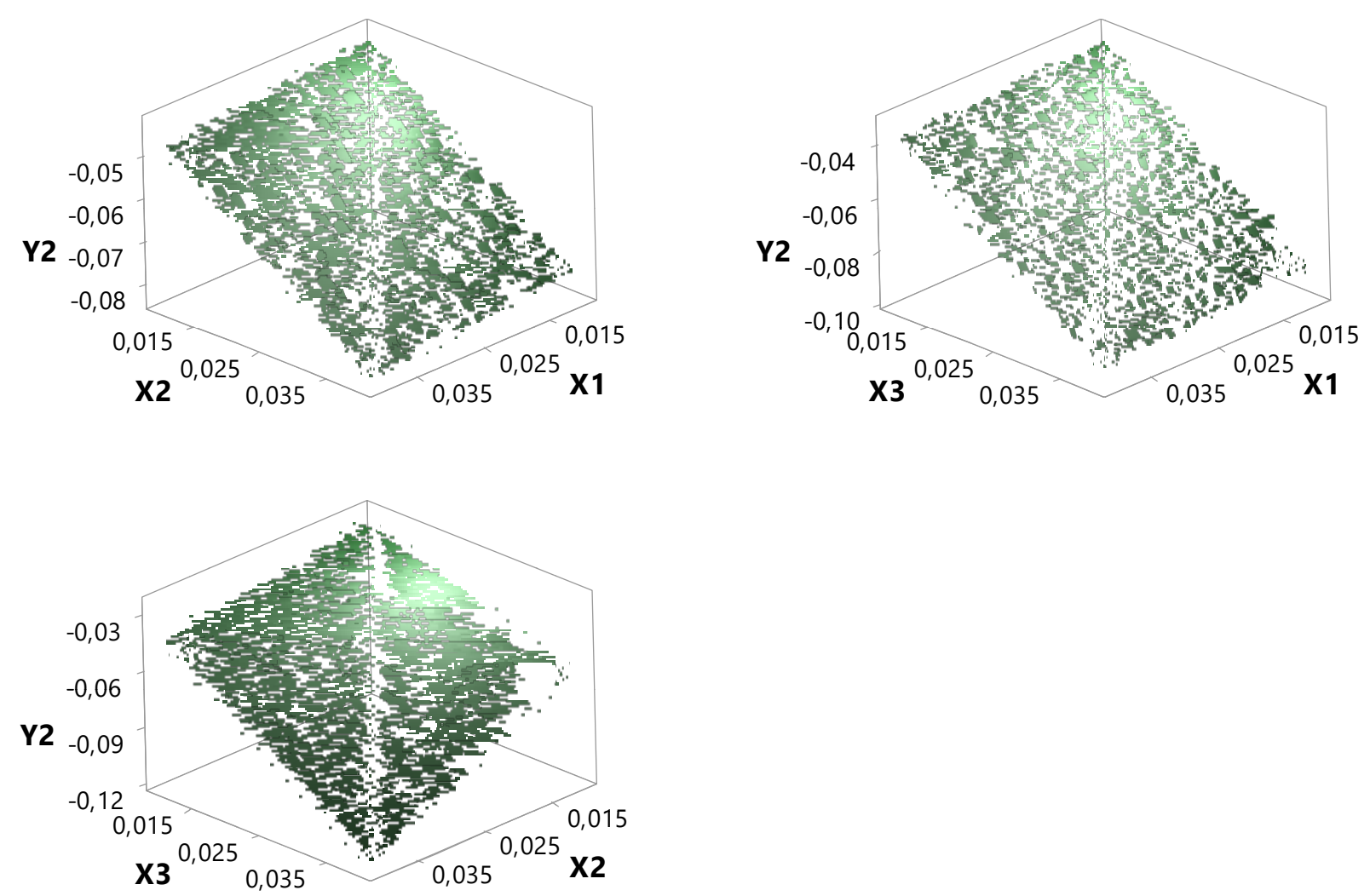

Figura 9. Gráficos 3D dos "slopes" para Escherichia coli (Y2) em função das concentrações de metilparabeno (X1), propilparabeno (X2) e isobutilparabeno (X3). Valores fixados em X1 $=0,025 \%, \mathrm{X} 2=0,025 \%$ e X3 $=0,025 \%$. 

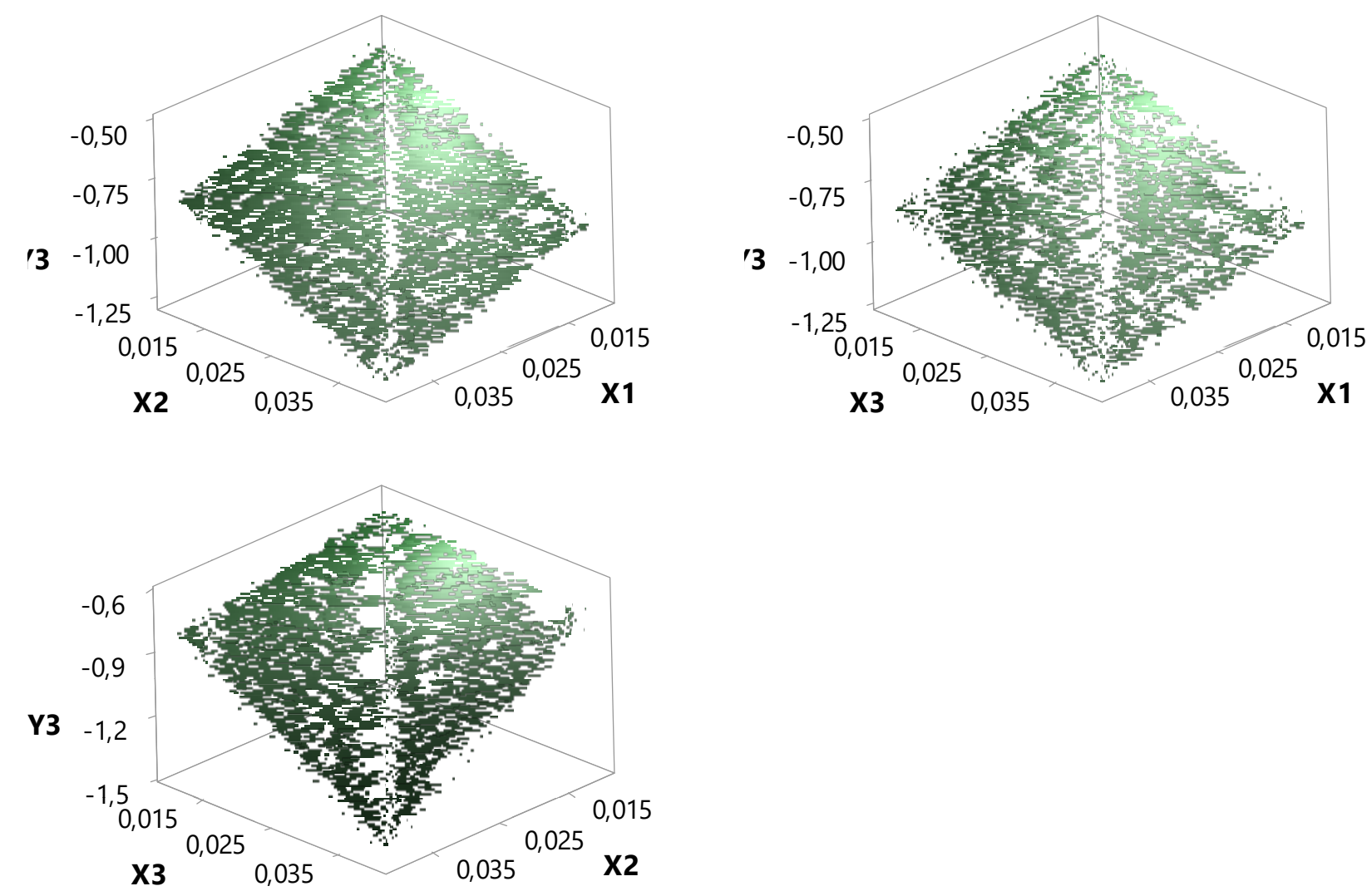

Figura 10. Gráficos 3D dos "slopes" para Staphylococcus aureus (Y3) em função das concentrações de metilparabeno (X1), propilparabeno (X2) e isobutilparabeno (X3). Valores fixados em X1 $=0,025 \%, \mathrm{X} 2=0,025 \%$ e X3 $=0,025 \%$. 
Para melhor compreensão quanto ao atendimento ou não as especificações, os valores de "slopes" obtidos a partir das curvas de morte microbiana de Candida albicans (Y1), Escherichia coli (Y2) e Staphylococcus aureus (Y3) foram convertidos em tempo necessário para a haver redução de 3 ciclos de log, conforme apresentado na Tabela 10. Segundo os requerimentos das farmacopeias americana e brasileira, para que um produto seja aprovado quanto ao teste de eficácia do sistema conservante, este deve apresentar redução de 3 ciclos de log após 14 dias, quando contaminado intencionalmente com cerca de $10^{6} \mathrm{UFC} / \mathrm{g}$ ou $\mathrm{mL}$.

Tabela 10. Resultados do tempo necessário para redução de 3 ciclos log para Candida albicans (Y1*), Escherichia coli (Y2*) e Staphylococcus aureus (Y3*), em função das concentrações de metilparabeno (X1), propilparabeno (X2) e isobutilparabeno (X3).

\begin{tabular}{ccccccc}
\hline \multirow{2}{*}{ Formulações } & \multicolumn{3}{c}{ Variáveis independentes } & \multicolumn{3}{c}{ Variáveis dependentes } \\
\cline { 2 - 7 } & $\mathbf{X 1}$ & $\mathbf{X 2}$ & $\mathbf{X 3}$ & Y1* & Y2* & Y3* \\
\hline 1 & 0,01 & 0,01 & 0,01 & 34,2 & 5,78 & 0,2465 \\
2 & 0,04 & 0,01 & 0,01 & 27,7 & 3,92 & 0,1613 \\
3 & 0,01 & 0,04 & 0,01 & 15,1 & 3,08 & 0,1810 \\
4 & 0,04 & 0,04 & 0,01 & 7,9 & 2,74 & 0,1342 \\
5 & 0,01 & 0,01 & 0,04 & 31,7 & 2,01 & 0,2254 \\
6 & 0,04 & 0,01 & 0,04 & 13,2 & 1,89 & 0,1303 \\
7 & 0,01 & 0,04 & 0,04 & 3,6 & 1,05 & 0,0956 \\
8 & 0,04 & 0,04 & 0,04 & 3,3 & 1,06 & 0,0804 \\
\hline
\end{tabular}


Os resultados de análise de variância (ANOVA) do tempo necessário para redução de 3 ciclos log para Candida albicans (Y1*), Escherichia coli (Y2*) e Staphylococcus aureus (Y3*), em função das concentrações de metilparabeno (X1), propilparabeno (X2) e isobutilparabeno (X3) estão apresentados na Tabela 11. As equações de regressão, assim como os coeficientes de determinação estão apresentados na Tabela 12.

Tabela 11. Resultados de ANOVA para o tempo necessário para redução de 3 ciclos log para Candida albicans (Y1*), Escherichia coli (Y2*) e Staphylococcus aureus (Y3*), em função das concentrações de metilparabeno (X1), propilparabeno (X2) e isobutilparabeno (X3).

\begin{tabular}{lcccccccccc}
\hline Fonte & & Y1 & & & Y2 & & & Y3 & \\
& gl & SQ & $\mathbf{P}$ & gl & SQ & $\mathbf{P}$ & gl & SQ & P \\
& & & & & & & & & & \\
\hline Regressão & 4 & 5,8382 & 0,015 & 3 & 2,46343 & 0,001 & 5 & 1,06633 & 0,018 \\
X1 & 1 & 0,4069 & 0,092 & 1 & 0,03974 & 0,154 & 1 & 0,26063 & 0,015 \\
X2 & 1 & 3,9448 & 0,005 & 1 & 0,61097 & 0,002 & 1 & 0,42032 & 0,009 \\
X3 & 1 & 1,2117 & 0,024 & 1 & 1,81272 & 0,000 & 1 & 0,26428 & 0,015 \\
X1*X2 & & & & & & & 1 & 0,03125 & 0,106 \\
X2*X3 & 1 & 0,2719 & 0,138 & & & & 1 & 0,08985 & 0,041 \\
Erro & 3 & 0,2048 & & 4 & 0,05170 & & 2 & 0,00786 & \\
Total & 7 & 6,0430 & & 7 & 2,51513 & & 7 & 1,07419 & \\
\hline
\end{tabular}


Tabela 52. Equações de regressão e coeficientes de determinação das velocidades de morte das formulações contendo diferentes concentrações de metilparabeno (X1), propilparabeno (X2) e isobutilparabeno (X3).

\begin{tabular}{lccc}
\hline \multicolumn{1}{c}{ Equações de regressão } & R2 & R2adj & R2pred \\
\hline $\mathrm{Ln}(\mathrm{Y} 1 *)=4,201-15,03 \mathrm{X} 1-26,2 \mathrm{X} 2-5,4 \mathrm{X} 3-824 \mathrm{X} 2 * \mathrm{X} 3$ & $96,61 \%$ & $92,09 \%$ & $75,90 \%$ \\
$\mathrm{Ln}(\mathrm{Y} 2 *)=2,209-4,70 \mathrm{X} 1-18,42 \mathrm{X} 2-31,73 \mathrm{X} 3$ & $97,94 \%$ & $96,40 \%$ & $91,78 \%$ \\
$\mathrm{Ln}(\mathrm{Y} 3 *)=-1,052-18,98 \mathrm{X} 1-10,45 \mathrm{X} 2-0,34 \mathrm{X} 3+277,8 \mathrm{X} 1 * \mathrm{X} 2-$ & $99,27 \%$ & $97,44 \%$ & $88,30 \%$ \\
$471 \mathrm{X} 2 * \mathrm{X} 3$ & & & \\
\hline
\end{tabular}

Os gráficos 3D do tempo necessário para redução de 3 ciclos log para os microrganismos: Candida albicans (ATCC 10231), Escherichi coli (ATCC 8739) e Staphylococcus aureus (ATCC 6538) estão apresentados nas Figuras 11, Figura 12 e Figura 13, respectivamente. Adicionalmente, a Figura 14 apresenta os gráficos de pareto e de efeitos principais do tempo necessário para redução de 3 ciclos log para Candida albicans (Y1*), Escherichia coli (Y2*) e Staphylococcus aureus (Y3*), em função das concentrações de metilparabeno (X1), propilparabeno (X2) e isobutilparabeno (X3). 

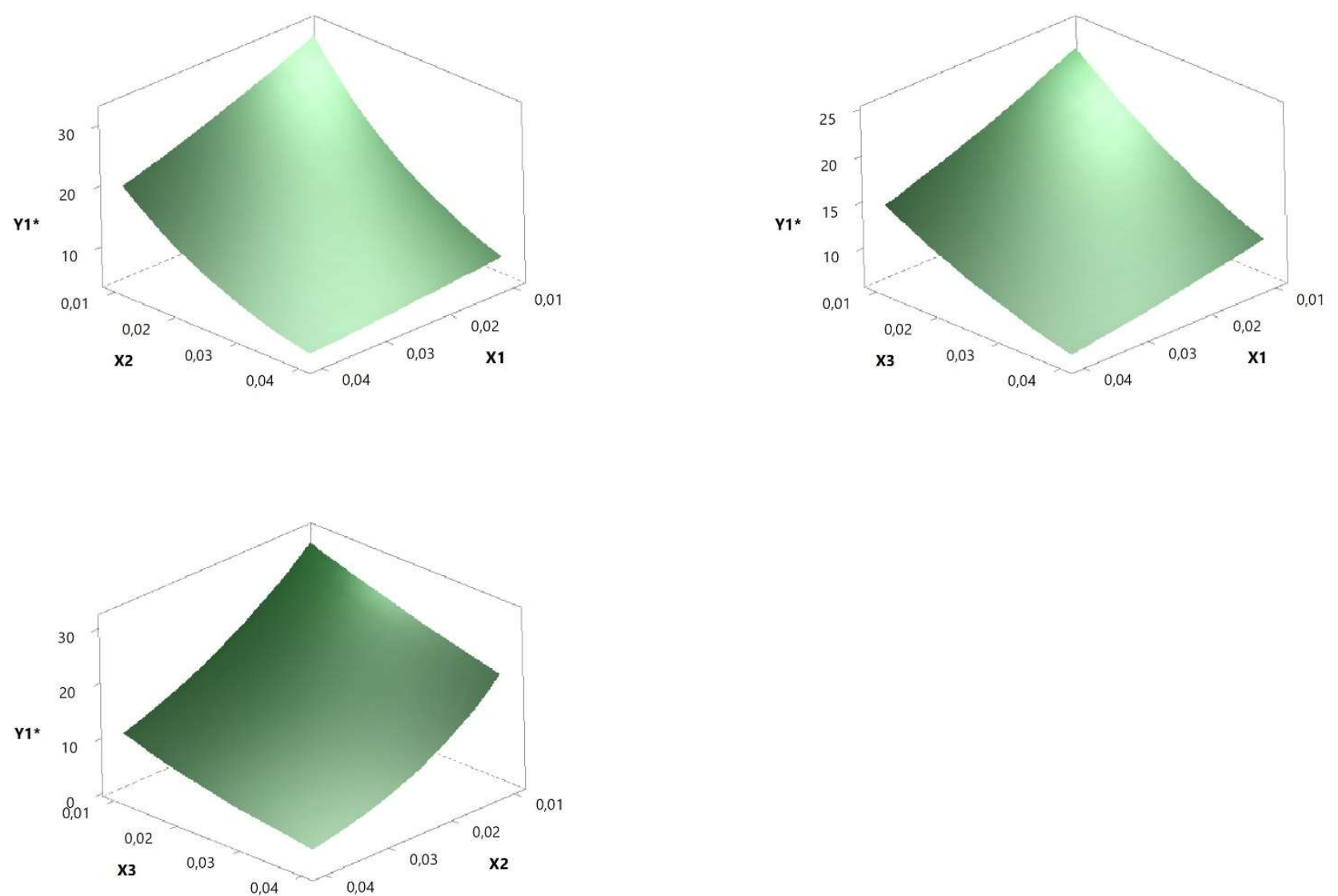

Figura 1. Gráficos 3D do tempo necessário para redução de 3 ciclos $\log$ para Candida albicans (Y1*) em função das concentrações de metilparabeno (X1), propilparabeno (X2) e isobutilparabeno (X3). Valores fixados em X1 =0,025\%, X2 =0,025\% e X3 =0,025\%. 

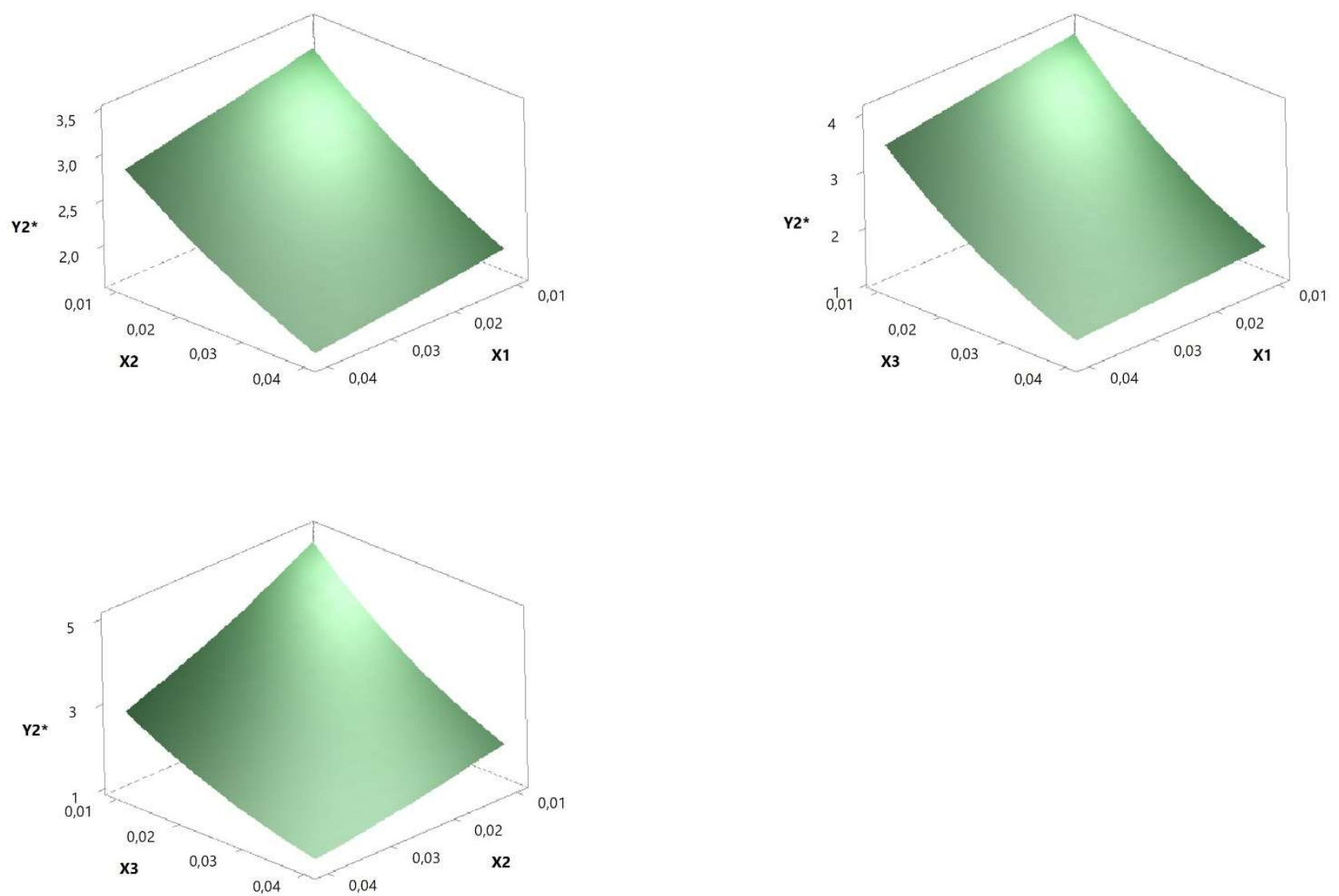

Figura 12. Gráficos 3D do tempo necessário para redução de 3 ciclos log para Escherichia coli (Y2*) em função das concentrações de metilparabeno (X1), propilparabeno (X2) e isobutilparabeno (X3). Valores fixados em X1 =0,025\%, X2 =0,025\% e X3 =0,025\%. 

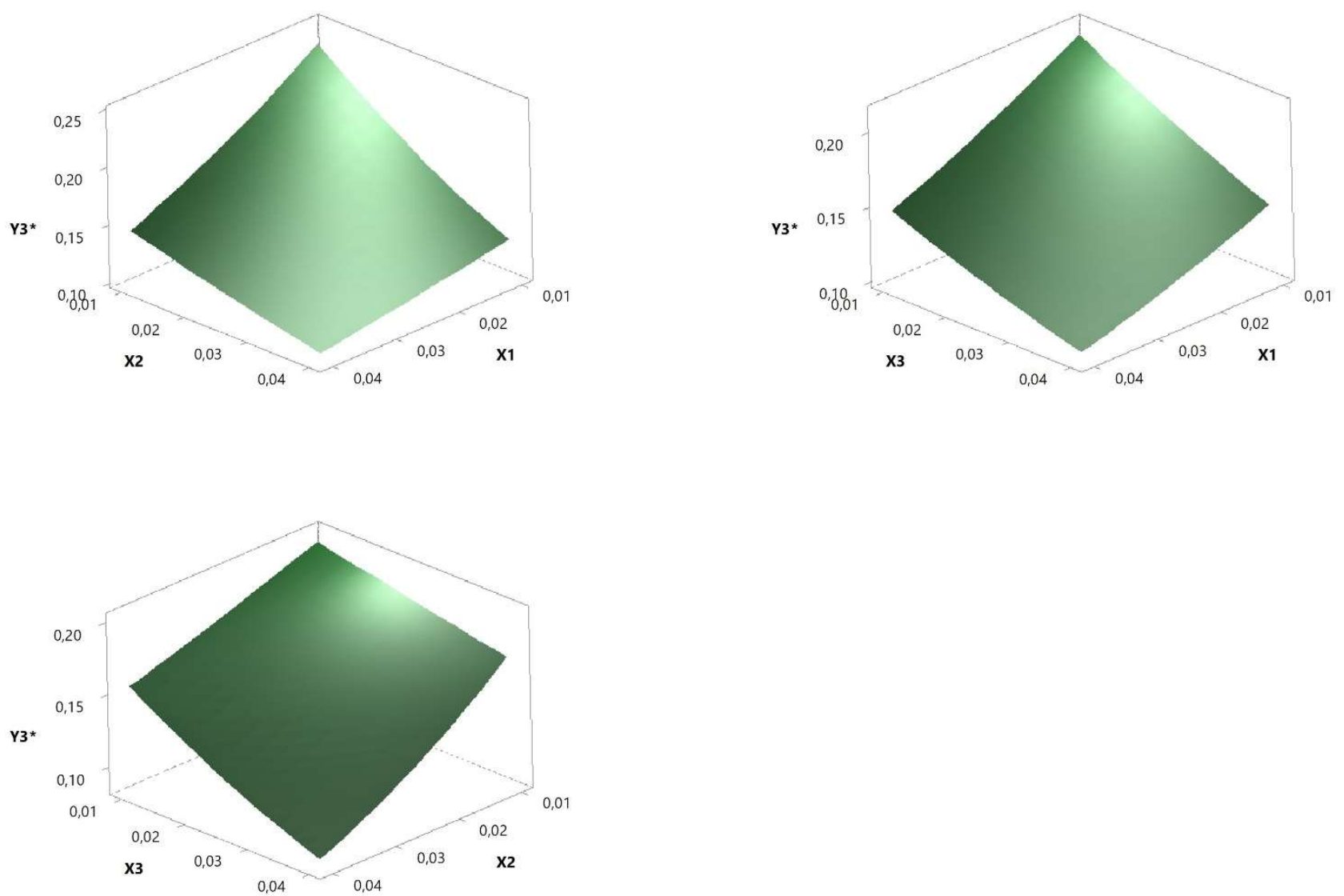

Figura 13. Gráficos 3D do tempo necessário para redução de 3 ciclos log para Staphylococcus aureus (Y3*) em função das concentrações de metilparabeno (X1), propilparabeno (X2) e isobutilparabeno (X3). Valores fixados em X1 =0,025\%, X2 = 0,025\% e X3 = 0,025\%. 

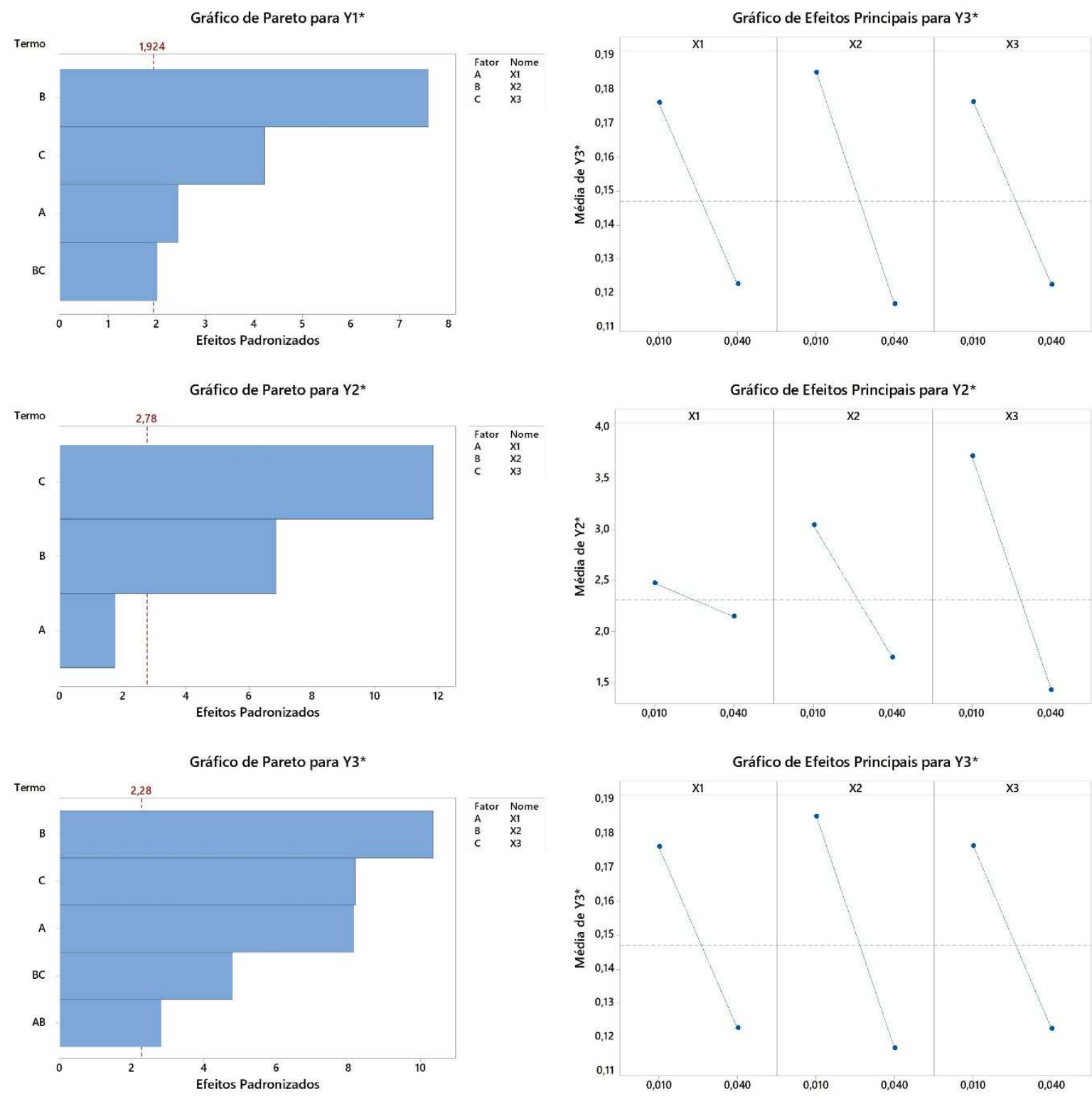

Figura 14. Gráficos de Pareto e de Efeitos Principais do tempo necessário para redução de 3 ciclos log para Candida albicans (Y1), Escherichia coli (Y2) e Staphylococcus aureus (Y3) em função das concentrações de metilparabeno (X1), propilparabeno (X2) e isobutilparabeno (X3). Valores fixados em X1 $=0,025 \%, \mathrm{X} 2=0,025 \%$ e X3 $=0,025 \%$. 
A partir das equações de regressão obtidas para o tempo necessário para redução de 3 ciclos log para Candida albicans (Y1), Escherichia coli (Y2) e Staphylococcus aureus (Y3) em função das concentrações de metilparabeno (X1), propilparabeno (X2) e isobutilparabeno $(\mathrm{X} 3)$ foi realizada uma otimização multiresposta, empregando o método de sobreposição dos gráficos de contorno. Como critérios para a construção dos gráficos de contorno, foram selecionadas as concentrações de metilparabeno (X1), propilparabeno (X2) e isobutilparabeno (X3) que resultassem num tempo de até 14 dias para a redução de 3 ciclos log para Candida albicans (Y1*), Escherichia coli (Y2*) e Staphylococcus aureus (Y3*). O resultado a otimização está apresentado na Figura 15. 

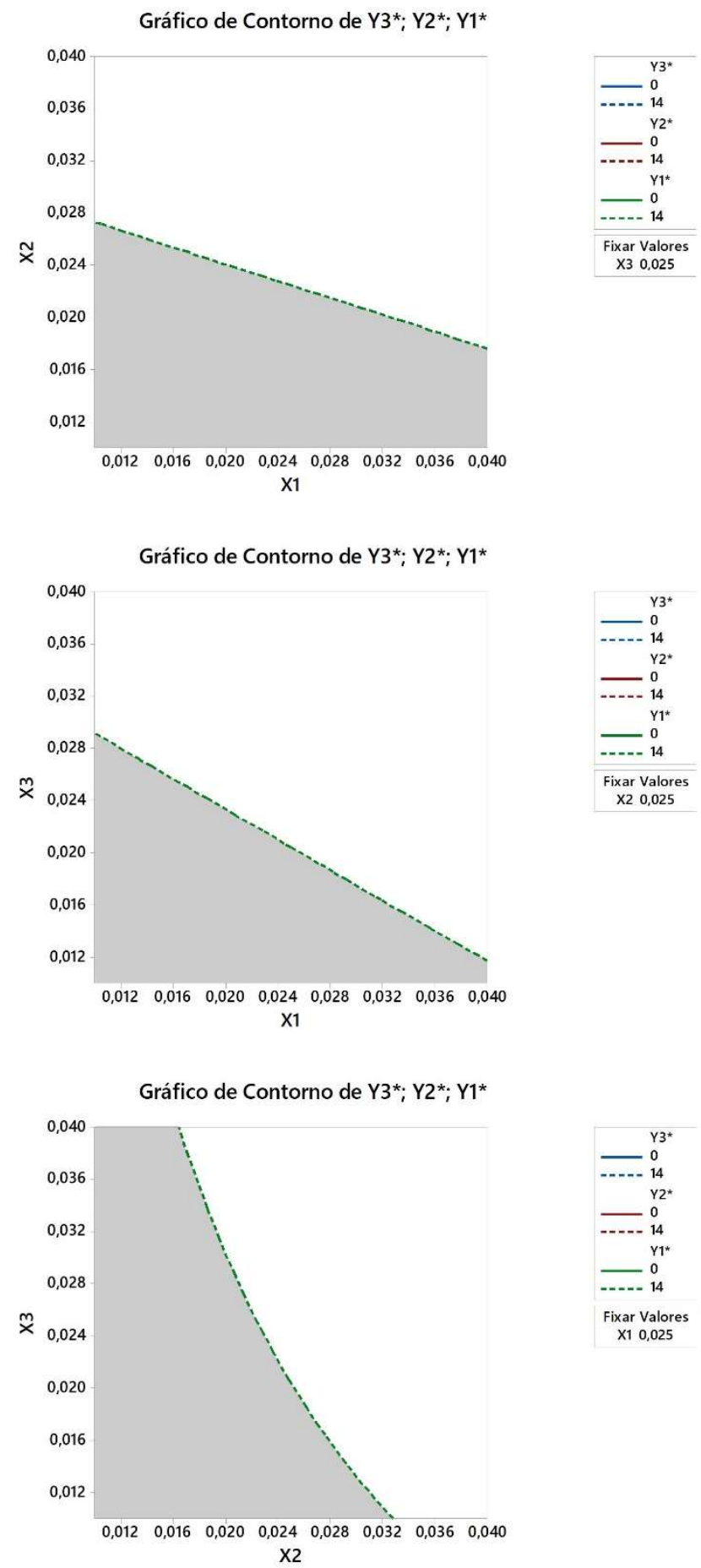

Figura 2. Gráficos de contorno sobrepostos do tempo necessário para redução de 3 ciclos log para Candida albicans (Y1), Escherichia coli (Y2) e Staphylococcus aureus (Y3) em função das concentrações de metilparabeno (X1), propilparabeno (X2) e isobutilparabeno (X3). 
Pode-se perceber que, na faixa de concentração de metilparabeno (X1), propilparabeno (X2) e isobutilparabeno (X3) estudada, a redução de 3 ciclos log para a Candida albicans (Y1) é o limitante. A formulação que apresenta concentrações de metilparabeno (X1), propilparabeno (X2) e isobutilparabeno (X3) em 0,025\%, 0,025\% e $0,025 \%$, respectivamente, foi aquela que atendeu aos requerimentos para a redução de 3 ciclos log para todos os microrganismos com a menor concentração de parabenos. Esta formulação foi, portanto, selecionada para a realização do teste de eficácia de conservantes convencional, segunda as farmacopeias americana e brasileira.

Os resultados do teste de eficácia de conservantes segundo as farmacopeias americana e brasileira para a formulação otimizada contendo metilparabeno $(\mathrm{X} 1=$ $0,025 \%)$, propilparabeno $(\mathrm{X} 2=0,025 \%)$ e isobutilparabeno $(\mathrm{X} 3=0,025 \%)$ estão apresentados na Tabela 13, ambos apresentaram resultados dentro da especificação com redução de 3 ciclos logs frente a contagem inicial.

Tabela 63. Teste de eficácia de conservantes segundo as farmacopeias americana e brasileira para a formulação otimizada contendo metilparabeno $(\mathrm{X} 1=0,025 \%)$, propilparabeno $(\mathrm{X} 2=0,025 \%)$ e isobutilparabeno $(\mathrm{X} 3=0,025 \%)$.

\begin{tabular}{|c|c|c|c|c|}
\hline Microrganismo & $\begin{array}{l}\text { Contagem } \\
\text { inicial (T0) }\end{array}$ & $\begin{array}{l}\text { Após } 14 \\
\text { dias } \\
\text { (T14) }\end{array}$ & $\begin{array}{c}\text { Após } 28 \\
\text { dias } \\
\text { (T28) }\end{array}$ & $\begin{array}{c}\text { Conclusão } \\
\text { do teste }\end{array}$ \\
\hline Candida albicans & $7,3 \times 10^{5}$ & $<10$ & $<10$ & Atende \\
\hline Escherichia coli & $3,1 \times 10^{7}$ & $1,4 \times 10^{2}$ & $1,2 \times 10^{2}$ & Atende \\
\hline Staphylococcus aureus & $4,7 \times 10^{7}$ & $1,7 \times 10^{2}$ & $4,5 \times 10^{1}$ & Atende \\
\hline
\end{tabular}


As boas práticas de fabricação de medicamentos estão adotando tecnologias analíticas inovadoras que permitam avaliar o processo em tempo real, realizar análise de risco de falhas, bem como demais ferramentas de qualidade e estatísticas visando à qualidade no ciclo produtivo.

A espectrometria no infravermelho, também conhecida como espectrometria vibracional, é a medição do comprimento de onda e intensidade da absorção de luz infravermelha de uma amostra. Ela baseia-se na natureza da interação da radiação IR com os modos de vibração de moléculas (RAKESH, CHARMIL, \& RAJESH, 2014). Os espectros de IR são devido às mudanças na energia vibracional, acompanhado por mudanças na energia rotacional (VIDYASAGAR, 2009). A absorção da radiação IR corresponde a mudanças de energia da ordem de 8-40 KJ / mol. O pré-requisito para a molécula para interagir com a radiação de IR é a presença de um dipolo permanente, que varia continuamente na sua radiação. Um espectrômetro infravermelho é um instrumento que passa luz infravermelha através de uma molécula orgânica e produz um espectro com o traçado da quantidade de luz transmitida no eixo vertical comparado com o comprimento de onda da radiação infravermelha no eixo horizontal.

Os métodos espectrométricos em associação com técnicas quimiométricas (ferramentas PCA e PLS) possibilitam a análise de misturas complexas sem a necessidade de preparação prévia das amostras, o que torna a técnica interessante para a avaliação da qualidade de produtos farmacêuticos e cosméticos em tempo real.

Os cremes contendo diferentes concentrações de metilparabeno, propilparabeno e isobutilparabeno foram analisadas por espectrofotometria ATR/FTIR. Os espectros na região de 800 a $2.600 \mathrm{~cm}^{-1}$ são apresentados na Figura 16. A regressão de PLS foi usada 
para estabelecer modelos matemáticos capazes de prever a taxa de mortalidade microbiana (inclinações de curvas de morte microbianas em função do tempo) com base nos espectros ATR/FTIR. Em outras palavras, os espectros ATR/FITR foram utilizados para prever as concentrações de metilparabeno, propilparabeno e isobutilparabeno nos cremes, que estão fortemente relacionadas com as taxas de mortalidade microbiana (valores de inclinação). Um total de 90 espectros obtidos a partir das 15 formulações de emulsão de creme foram utilizados na análise de regressão de PLS, com 48 espectros sendo utilizados na construção e validação interna (validação cruzada) do modelo de predição e 42 espectros utilizados na validação externa. 


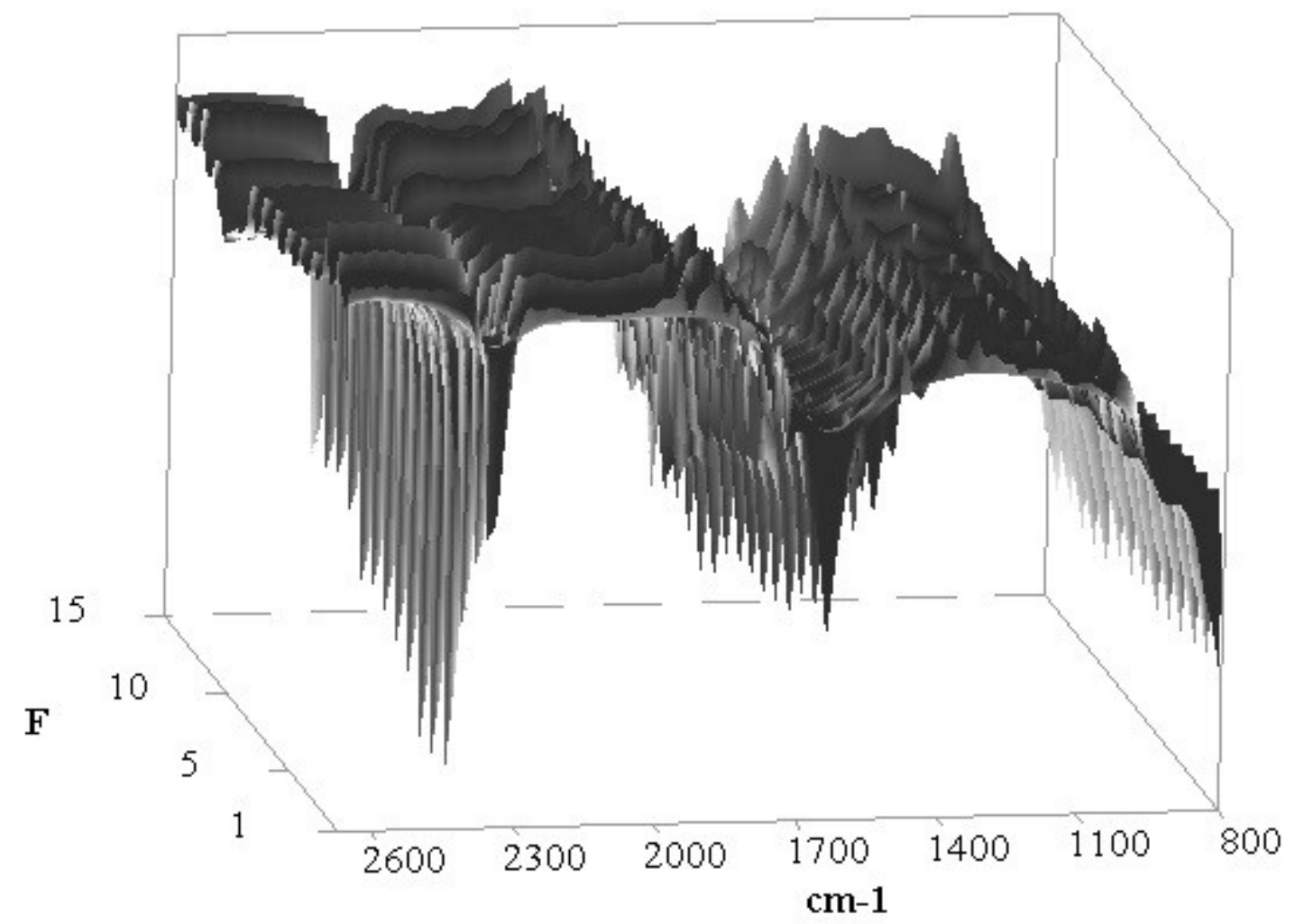

Figura 3. Espectros de FTIR de formulações (F1 a F15) na região de 800 a $2600 \mathrm{~cm}^{-1}$ utilizados para construir o modelo de regressão PLS para prever os "slopes" das curvas de morte microbiana de Candida albicans (Y1), Escherichia coli (Y2), e Staphylococcus aureus (Y3). 
Um resumo dos resultados na análise de regressão por mínimos quadrados parciais (PLS) para a predição das velocidades de morte de cada microrganismo estão apresentados na Tabela 14. Os gráficos de resposta para cada microrganismo são utilizados para avaliar a capacidade do modelo em realizar predições das velocidades de morte de cada microrganismo a partir dos espectros de IR. Adicionalmente, estes gráficos fornecem informação sobre os resultados da validação cruzada e permitem determinar o número de componentes principais $(\mathrm{CP})$ ideal para o modelo.

Tabela 7. Resumo dos resultados da análise de regressão por mínimos quadrados parciais (PLS) para a predição das velocidades de morte de cada microrganismo.

\begin{tabular}{lcccc}
\hline Microrganismo & $\mathbf{N}^{\mathbf{0}}$ de CP & R2 & R2pred & P-valor \\
\hline Candida albicans & 15 & 0.993691 & 0.892115 & $<0.001$ \\
Escherichia coli & 15 & 0,994730 & 0,878274 & $<0.001$ \\
Staphylococcus & 15 & 0,995676 & 0,922177 & $<0.001$ \\
aureus & & & & \\
\hline
\end{tabular}

Os gráficos de dispersão dos "slopes" preditos a partir dos espectros das amostras versus os "slopes" experimentais, considerando os resultados do ajuste do modelo, da validação interna (cruzada) e da validação externa, frente aos microrganismos: Candida albicans (ATCC 10231), Escherichi coli (ATCC 8739) e Staphylococcus aureus (ATCC 6538). Durante a validação do método foi possível verificar que tanto os resultados obtidos experimentalmente (•), quanto os valores de predição (•) apresentaram boa previsibilidade de modelo ao se utilizar os valores obtidos nos espectros, apresentaram 
$\mathrm{R}^{2} \geq 0.90$, preconizado para métodos alternativos pela Farmacopéia Americana, 2019, conforme apresentados nas Figuras 17, Figura 18 e Figura 19, respectivamente. 


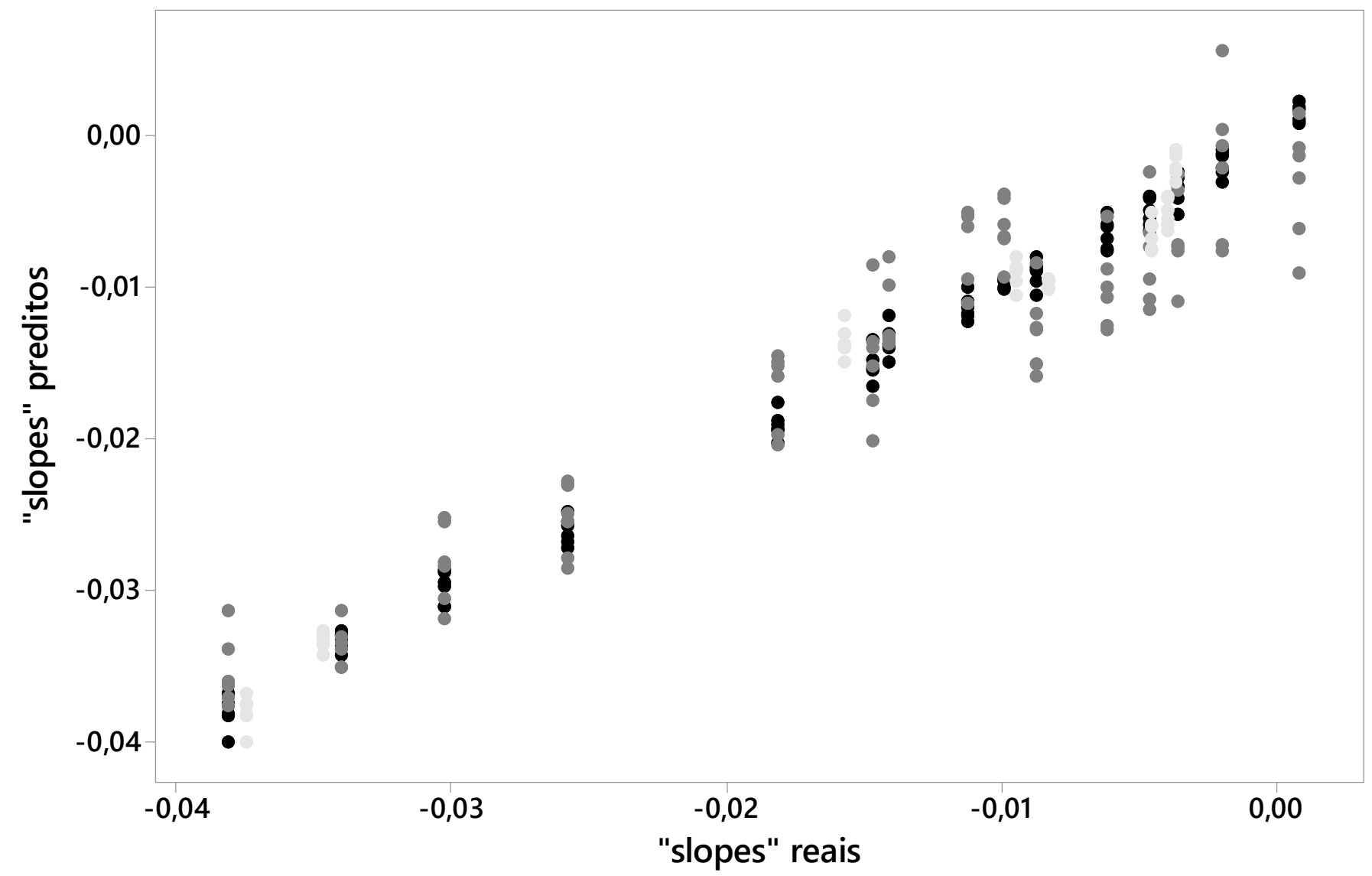

$R^{2}=99 \%$

$\mathrm{R}^{2}$ predição $=89 \%$

Figura 4. Gráficos de resposta (capacidade de predição) para o ajuste do modelo $(\bullet)$, validação interna - cruzada $(\bullet)$, e validação externa $(\bullet)$ para a predição dos “slopes” para Candida albicans a partir dos espectros de IR. 


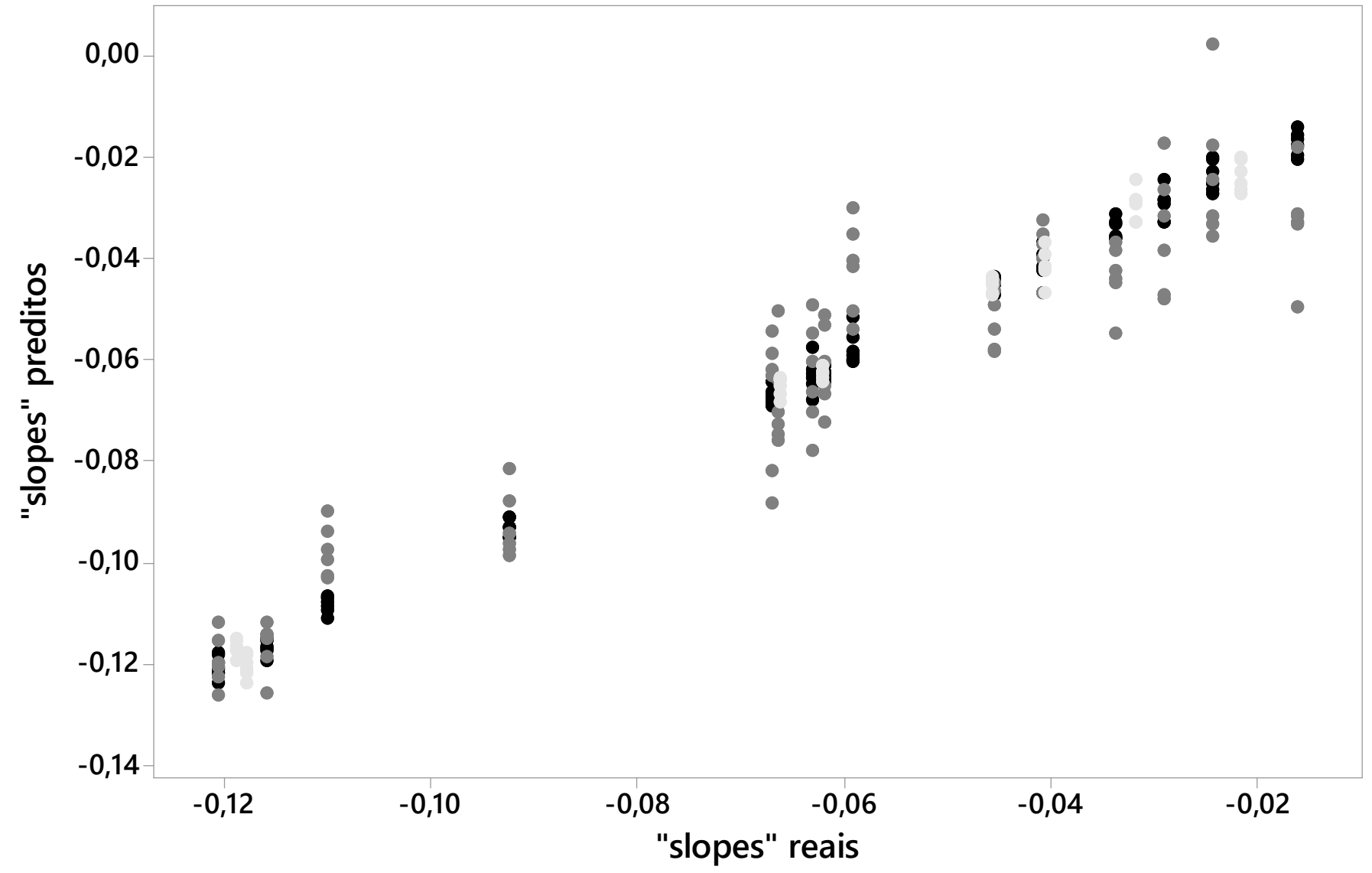

$R^{2}=99 \%$

$R^{2}$ predição $=88 \%$

Figura 58. Gráficos de resposta (capacidade de predição) para o ajuste do modelo (•), validação interna - cruzada (•), e validação externa ( ) para a predição dos "slopes" para Escherichia coli a partir dos espectros de IR 


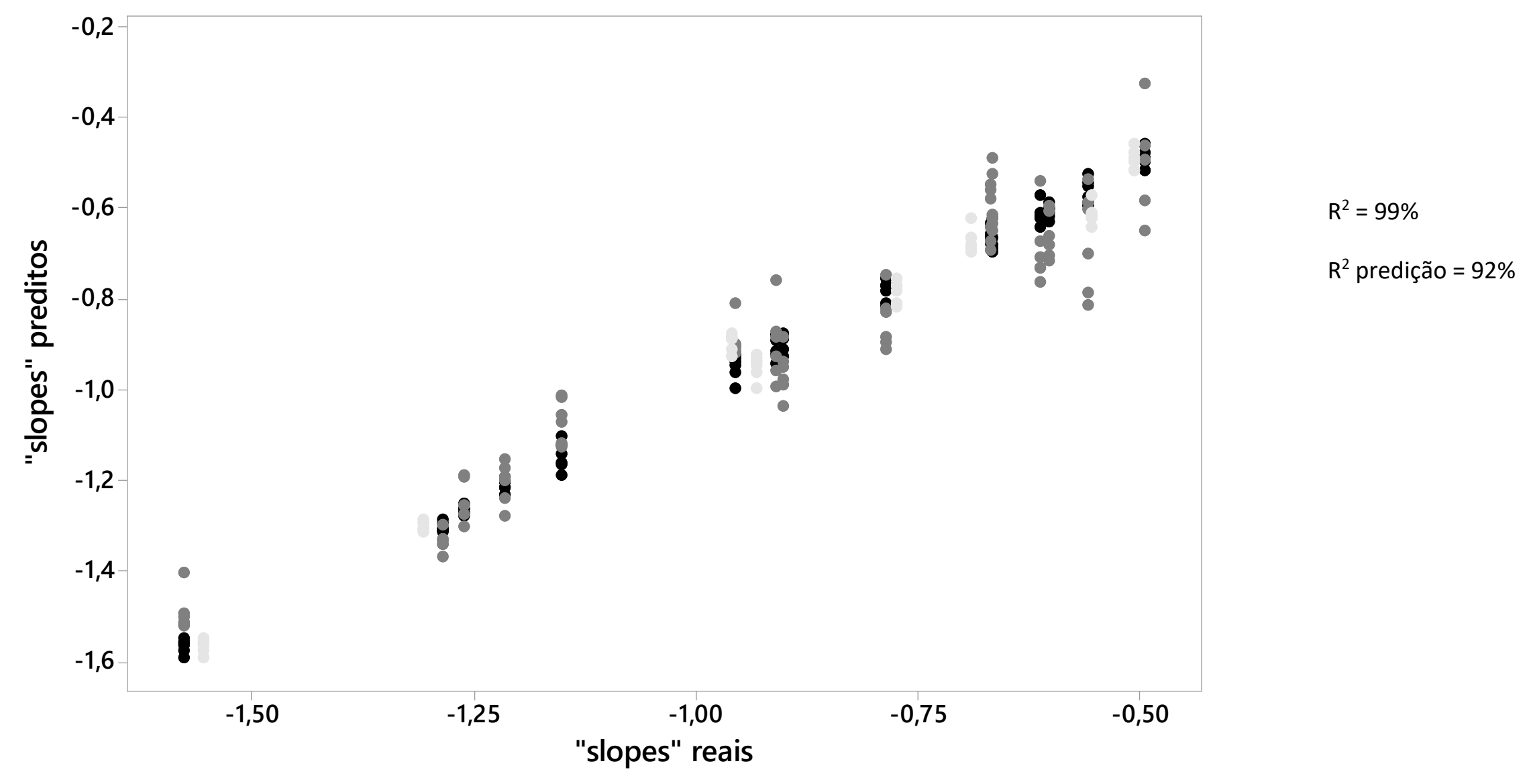

Figura 19. Gráficos de resposta (capacidade de predição) para o ajuste do modelo (•), validação interna - cruzada (•), e validação externa (•) para a predição dos “slopes”" para Staphylococcus aureus a partir dos espectros de IR. 

CONCLUSÕES 



\section{CONCLUSÕES}

- A técnica do número mais provável em microplacas foi adequada para a avaliação da eficácia dos sistemas conservantes frente a microrganismos padrão, permitindo reduzir a quantidade de material e, consequentemente os custos do ensaio;

- O delineamento de compósito central permitiu estabelecer como as concentrações dos parabenos afetam a eficácia do sistema conservante frente aos 3 microrganismos testados, permitindo estabelecer a região de Design Space, assim como a formulação com quantidades mínimas ideais de parabenos;

- O método espectrometria no infravermelho desenvolvido foi capaz de quantificar os parabenos presentes nas amostras de creme e, indiretamente, predizer a eficácia dos sistemas conservantes em tempo reduzido. Este método de predição de silico permitirá um controle lote-a-lote da eficácia do sistema conservante de produtos farmacêuticos e cosméticos.

Diante do exposto, podemos concluir que a aplicação dos conceitos de QbD e PAT possibilitaram o desenvolvimento racional de sistemas conservantes, assim como a avaliação de sua eficácia em tempo reduzido. 

REFERÊNCIAS 



\section{REFERÊNCIAS}

APONTE, O.F.G.; DÍAZ, B.M.; HUERTAS, C.E.M.; La calidade desde El diseño: 95glomerado y oportunidades para la 95glomerad 95glomerados95. Estudios Gerenciales, p. 68-78, 2015.

ASSOCIAÇÃO BRASILEIRA DE NORMAS TÉCNICAS. NBR ISO 9000: 2008Sistema de Gestão da Qualidade: Fundamentos e Vocabulário. Rio de Janeiro, ABNT, 2008.

BEZERRA, M.A.; SANTELLI, R.E.; OLIVEIRA, E.P.; VILLAR, L.S.; ESCALEIRA, L.A. Response surface methodology (RSM) as a tool for optimization in analytical chemistry. Talanta., p. 965-977, 2008.

BEZERRA, M.P.; RODRIGUES, L.N.C. Quality by Design (QbD) como ferramenta para otimização de processos farmacêuticos. Infarma Ciências Farmacêuticas. V.29, $\mathrm{n}^{\mathrm{o}} 1, \mathrm{p} .5-12,2017$.

BHUTANI, H.; KURMI, M.; SINGH, S.; BEG, S.; SINGH, B. Quality by design (QbD) in analytical sciences: an overview. Pharma Times, p- 71-75, 2014.

BLEDZKA, D., GROMADZINSKA, J., AND WASOWICZ, W. Parabens. From environmental studies to human health. Environ. Int. 67, 27-42, 2014.

BRASIL. ANVISA - AGÊNCIA NACIONAL DE VIGILÂNCIA SANITÁRIA. $5^{\mathrm{a}}$ ed. Brasília, $2010 \mathrm{~b}$.

BRASIL. ANVISA - AGÊNCIA NACIONAL DE VIGILÂNCIA SANITÁRIA. Resolução - RDC N ${ }^{\circ}$ 162, 2001.

BRASIL. ANVISA - AGÊNCIA NACIONAL DE VIGILÂNCIA SANITÁRIA. Resolução, RDC n 17, 2010a.

BRASIL. ANVISA - AGÊNCIA NACIONAL DE VIGILÂNCIA SANITÁRIA. Portaria, RDC n ${ }^{\circ} 782,2008$.

BRIONES Jr., A.M., REICHARDT, W. Estimating microbial population counts by 'most probable number' using Microsoft Excel ${ }^{\circledR}$. Journal of Microbiological Methods, p-157-191, 1999.

CANDIOTI, L.V.; DE ZAN, M.M.; CÁMARA, M.S.; GOICHOECHEA, H.C., Experimental design and multiple response optimization. Using the desirability function in analytical methods development. Talanta., p-123-138, 2014.

CARVALHO, R., Combinação de infravermelho próximo e ferramentas quimiométricas para análise de material desfibrado de cana de açúcar. 2015. 214 f. Dissertação (Mestrado) - Centro de ciências exatas e de tecnologia, Universidade de São Carlos, São Carlos.

CAVAZZUTI, M., Optimization Methods: From Theory to Design Scientifica and Thechnological Aspects in Mechanics. Springer-Verlag Berlin Heidelberg, 2013.

CHALLA, S; POTUMARTHI, R, Chemometrics-Based Process Analytical Technology (PAT) Tools: Applications and Adaptation in Pharmaceutical and 
Biopharmaceutical Industries. Applied Biochemistry and Biotechnology, p.6676, 2012.

CIR - Cosmetic Ingredient Review Expert Panel. Final Amended Report on the Safety Assessment of Methylparaben, Ethylparaben, Propylparaben, Isopropylparaben, Butylparaben, Isobutylparaben, and Benzylparaben as used in Cosmetic Products. International Journal of Toxicology, p. 1-82, 2008.

CURTIVO, C.P., Avaliação do processo de fabricação de comprimidos de Captopril (25mg): aplicação da tecnologia analítica de proesso e de ferramentas da qualidade e estatística, 2011. 214 f. Dissertação (Mestrado) - Faculdade de Ciências Farmacêuticas da Universidade de São Paulo, São Paulo.

FDA, Good Manufacturing Practices - CFR - Code of Federal Regulations Title 21, 2019.

FUKUDA, I.M.; PINTO C.F.F.; MOREIRA, C.S.; ET AL. Design of Experiments (DoE) applied to Pharmaceutial and Analytical Quality by Design (QbD). Brazilian Journal of Pharmaceutical Sciences, 2018.

GAFANIZ, S.M.M., Desenho de Garantia da qualidade: Projecto Mudança de Instalações. 2011. 176 f. Dissertação (Mestrado em Engenharia Farmacêutica) Faculdade Farmácia da Universidade de Lisboa, Lisboa.

INTERNATIONAL CONFERENCE ON HARMONISATION. Pharmaceutical Development. Q8 (R2), 2009.

LIAO, X., RAGHAVAN, G.S., AND YAYLAYAN, V. A novel way to prepare nbutylparaben under microwave irradiation. Tetrahedron Lett. 43, 45-48, 2002.

OMS, Boas Práticas de Fabricação, 2003.

PERAMAN, R.; BHADRAYA, K.; REDDY, Y.P.; Analytical quality by design: a tool for regulatory flexibility and robust analytics. Int J Anal Chem., p. 1-9, 2015.

PERES, D.D.; ARIEDE, M.B.; CANDIDO, T.M., Quality by design (QbD), Process analytical Technology (PAT), and design of experiment applied to the development of multifunctional sunscreens. Drug Development and Industrial Pharmacy, v.43, n², p.246-256, 2017.

PINTO, M.S.; ALPIOVEZZA, A.R.; RIGHETTI, C. Garantia da Qualidade na Indústria Cosmética.São Paulo, Cengage Learning, 2012.

PINTO, T.J.A.; KANEKO, T.M.; PINTO, A.F. Controle Biológico de Qualidade de Produtos Farmacêuticos, Correlatos e Cosméticos. Ed. Manole, 4 ed., p. 01-05, 2015.

POLITIS, S.N.; COLOMBO, P.; COLOMBO, G.; REKKAS, D.M., Design of experiments (DoE) in pharmaceutical development. Drug Develop Ind Pharm, p.889-901, 2017.

Q10(R2). ICH - HARMONISED TRIPARTITE GUIDELINE. Pharmaceutical Quality System. Current step 4 version, 2008.

Q8(R2). ICH - HARMONISED TRIPARTITE GUIDELINE. Pharmaceutical Development. Current step 4 version, 2009. 
Q9(R2). ICH - HARMONISED TRIPARTITE GUIDELINE. Quality Risk Management. Current step 4 version, 2005.

RAKESH, P.; CHARMIL, P.; RAJESH, K. S. Quantitative Analytical applications of FTIR Spectroscopy in Pharmaceutical and Allied Areas. Journal of Advanced Pharmacy Education \& Research, vol 4, p. 145-157, 2014.

RATHORE, A.S; WINKLE, H. Quality by design for biopharmaceuticals. Nature Biotechnology, v. 27, p. 26-34, 2009.

SALEME, H.R; JULIO, J.E.C.; HUERTAS, C. E.M. Aplicación de la calidad basada en el diseño (QbD) en la reformulación de tabletas Masticables. Rev. Colomb. Cienc. Quím. Farm., vol. 42, p. 190-214, 2013.

SANGSHETTI, J.N.; DESHPANDE M.; ZAHEER, Z.; SHINDE, D.B.; AROTE R. Quality by design approach: Regulatory need. Arabian Journal of Chemistry, p. $1-14,2014$.

SANGSHETTI, J.N.; DESHPANDE M.; ZAHERR Z.; SHINDE, D.B.; AROTE, R. Quality by design approach: regulatory need. Arab J Chem., p. 3412-3425, 2017.

SCCS - SCIENTIFIC COMMITTEE ON CONSUMER SAFETY. The SCCS'S notes of guidance for the testing of cosmetic substances and their safety evaluation $8^{\text {a }}$ Revision. SCCS 1501/12. 2012. Disponível em < http://ec.europa.eu > acessado em 04 de fevereiro de 2018.

SHIVHARE, M.; McCREATH, G. Practical Considerations for DoE Implementation in Quality by Design. BioProcess International, p. 22-30, 2010.

SIMÕES, S.S. Desenvolvimento de métodos validados para a determinação de captopril usando espectrofotometria NIR e calibração multivariada. Tese (Doutorado em Ciências), , 2008 - Departamento de Química, Universidade Federal da Paraíba, João Pessoa.

TAVARES, A.T, PEDRIALI, C.A., Relação do uso de parabenos em cosméticos e sua ação estrogênica na indução do câncer no tecido mamário. Revista Multidisciplinar da saúde - Ano III - nº6, 2011.

UNITED STATES PHARMACOPEIA, cap. 1223, Ed. 39, 2019.

UNITED STATES PHARMACOPEIA, cap. 51, Ed. 39, 2019.

UNITED STATES PHARMACOPEIA, cap. 1223, Ed. 39, 2019.

VALKOVA, N. et al. Hydrolysis of 4-Hydroxybenzoic Acid Esters (Parabens) and Their Aerobic Transformation into Phenol by the Resistant Enterobacter cloacae Strain EM. Université du Québec, Canadá, jun. 2001.

VIDYASAGAR, G. Instrumental methods of drug analysis. Pharma Med Press, p. 365 $-387,2009$.

YU, L.X.; AMIDON, G., KHAN, M.A., HOAG, S.W.; POLLI J.; RAJU, G.K.; WOODCOCK, J. Understanding pharmaceutical quality by design. AAPS J., p- 771-783,2014. 
